\title{
Perspectivas filosóficas de los valores superiores: un intento de redefinición como identidad y patrimonio de los pueblos
}

\author{
Liuba Galbán-Rodríguez \\ Neris Rodríguez-Matos ${ }^{\star *}$
}

* Magíster en Derecho Civil y de Familia. Profesora auxiliar, Universidad de Oriente, Santiago de Cuba, Cuba.

Correo electrónico: lgalban@uo.edu.cu

** Doctora en Filosofía. Profesora consultante, Universidad de Oriente, Santiago de Cuba, Cuba.

Correo electrónico: neris@uo.edu.cu

Recibido: 19 de diciembre del 2016 Aprobado: 29 de enero del 2017

Cómo citar este artículo: Liuba GalbánRodríguez, Neris Rodríguez-Matos. Perspectivas filosóficas de los valores superiores. Un intento de redefinición como identidad y patrimonio de los pueblos. DIXI 26. Mayo 2017. Pág. 15. doi: http://dx.doi. org/10.16925/di.v19i26.1949

\section{Resumen}

Propósito: ofrecer una redefinición de los valores constitucionales, al considerarlos como parte de la identidad y el patrimonio intangible de los pueblos, producto de condicionantes históricas, políticas, económicas y socio-culturales concretas. Descripción: se desarrolla una breve retrospectiva de las principales concepciones de los valores en el pensamiento iusfilosófico, así como se responden interrogantes tales como si el reconocimiento de valores por las constituciones es producto del azar histórico, por qué tienen el apelativo de "superiores" o "supremos" del ordenamiento jurídico, si forman o no parte del derecho positivo, cuál es su relación con los derechos y si es suficiente con su reconocimiento constitucional para lograr su efectiva realización en la sociedad. Punto de vista: los valores reconocidos en las constituciones expresan ideologías, ideales y aspiraciones; son reflejos de pensamientos sociales, políticos, iusfilosóficos e irradian a todos los órdenes derivados de la Constitución. Conclusiones: los valores superiores son parte de la identidad y del patrimonio intangible de los pueblos, especialmente cuando su reconocimiento es producto de procesos constituyentes democráticos, cuentan con la supremacía jerárquica de la fuente de donde provienen, forman parte del derecho positivo y pueden ser directamente invocables, interpretables y aplicables.

Palabras clave: axiología, Constitución, derechos, patrimonio intangible, supremacía constitucional, valores superiores. 


\title{
Philosophical Perspectives of Superior Values: An Attempted Redefinition as Identity and Heritage of Peoples
}

\begin{abstract}
Purpose: To offer a redefinition of constitutional values by considering them as part of the identity and intangible heritage of peoples as a result of specific historical, political, economic and socio-cultural conditions. Description: A brief retrospective of the main conceptions of values in the legal philosophical thought is elaborated. Questions such as whether the recognition of values by constitutions arises from historical chance, why they are called "higher" or "superior" in the legal system, whether or not they are part of positive law, what their relationship to rights is, and whether their constitutional recognition is sufficient to enforce them in society are answered. Point of view: The values recognized in constitutions express ideologies, ideals and aspirations; they are reflections of social, political, legal philosophical thoughts and radiate to all the systems derived from the Constitution. Conclusions: Superior values are part of the identity and intangible heritage of peoples, especially when they are recognized because of democratic constituent processes, have the hierarchical supremacy of the source they come from, are part of positive law, and can be directly invokable, interpretable and applicable.
\end{abstract}

Keywords: axiology, Constitution, rights, intangible heritage, constitutional supremacy, superior values.

\section{Perspectivas filosóficas dos valores superiores: uma tentativa de redefinição como identidade e patrimônio dos povos}

\section{Resumo}

Propósito: oferecer uma redefinição dos valores constitucionais ao considerá-los como parte da identidade e do patrimônio intangível dos povos, produto de condicionantes históricas, políticas, econômicas e socioculturais concretas. Descrição: desenvolve-se uma breve retrospectiva das principais concepções dos valores no pensamento jusfilosófico bem como se respondem a interrogantes como se o reconhecimento de valores pelas constituições é produto do acaso histórico, por que têm o apelativo de "superiores" ou "supremos" do ordenamento jurídico, se fazem ou não parte do direito positivo, qual é sua relação com seus direitos e se basta seu reconhecimento constitucional para atingir sua efetiva realização na sociedade. Ponto de vista: os valores reconhecidos nas constituições expressam ideologias, ideais e aspirações; são reflexos de pensamentos sociais, políticos e jusfilosóficos e irradiam a todas as ordens derivadas da Constituição. Conclusões: os valores superiores fazem parte da identidade e do patrimônio intangível dos povos; em especial, quando seu reconhecimento é produto de processos constituintes democráticos, contam com a supremacia hierárquica da fonte da qual provêm, fazem parte do direito positivo e podem ser diretamente invocáveis, interpretáveis e aplicáveis.

Palavras-chave: axiologia, Constituição, direitos, patrimônio intangível, supremacia constitucional, valores superiores. 


\section{INTRODUCCIÓN}

Desde hace décadas, y debido a determinadas condicionantes históricas, económicas y socio-culturales, han aparecido todo un conjunto de constituciones iberoamericanas ${ }^{1}$ con sistemas basados en valores, bien sean reconocidos expresamente en preceptos determinados, o bien en preámbulos que, por albergarlos, han alcanzado poder vinculante por la jurisprudencia nacional. ${ }^{2}$ De ahí la importancia que ha adquirido el tema de los valores constitucionales, pues en el nuevo constitucionalismo se procura convertir a la Constitución prácticamente omnipresente en toda operación de creación y aplicación del derecho. Como consecuencia de esto, las relaciones entre legislación y jurisdicción se han modificado de manera sustancial, pues se pretende que el juicio de validez de la ley dependa de un juicio en conformidad con la Constitución, y sus valores por parte de todo el que esté llamado a interpretarla y a aplicarla. ${ }^{3}$

Los valores constitucionales son un ejemplo de un sistema institucionalizado de valores que se expresan por medio de diferentes vías, tales como la ideología, la política, el derecho y la educación. No obstante, ese sistema oficial de valores puede tener un mayor o

1. Véase Constitución Española de 1978 [Const]. Artículo 1. (España). Disponible en http://www.boe.es/buscar/pdf/ 1978/ BOE-A-1978-31229-consolidado.pdf; Constitución Política de Colombia de 1991. [Const]. Precepto 1. Julio 7 de 1991. (Colombia). Disponible en http://pdba.georgetown.edu/Constitutions/Colombia/vigente.html; Constitución del Salvador de 1983. [Const]. Artículo 1. (El Salvador). Disponible en http://pdba.georgetown. edu/Constitutions/ElSal/constitucion.pdf; Constitución de la Nación Argentina de 1994. [Const]. Preámbulo. (Argentina). Disponible en http://pdba.georgetown.edu/Constitutions/Argentina/argen94.html; Constitución de la República Bolivariana de Venezuela de 1999. [Const]. Artículos 1 y 2. (Venezuela). Disponible en http://www.mp.gob.ve/LEYES/constitucion/constitucion1. html; Constitución Política del Estado de Bolivia de 2009. [Const] Precepto 8.II. (Bolivia). Disponible en http://pdba.georgetown. edu/Constitutions/Bolivia/bolivia09.html; y Constitución de la República Dominicana de 2010. Artículos 5, 6, 7, y 8. [Const]. (República Dominicana). Disponible en http://pdba.georgetown. edu/Constitutions/DomRep/vigente.html

2. La Corte Constitucional de Colombia juzgó que el Preámbulo goza de poder vinculante, al contener los valores que esa Constitución aspira a realizar y que trasciende la pura literalidad de sus artículos. Véase Corte Constitucional de Colombia. Sentencia 479/13. (mp José G. Hernández y Alejandro Martínez C.: Agosto 13 de 1992). Disponible en http://www.corteconstitucional.gov.co/relatoria/1992/c-479-92.htm; Corte Constitucional de Colombia. Sentencia 126/98. (mp Alejandro Martínez C.: Abril 1 de 1998). Disponible en http://www.corteconstitucional.gov.co/ relatoria/1998/C-126-98.htm

3. Véase Luis M. Cruz. La Constitución como orden de valores. Reflexiones en torno al neoconstitucionalismo. Díkaion 18. Año 23. Diciembre de 2009. Pág. 16. menor grado de correspondencia con los valores de la sociedad, de sus miembros y la interpretación de cada individuo, en dependencia de contextos históricos, realidades políticas, económicas, socio-culturales y del tipo de proceso constituyente, así como de quién o cuál grupo ostenta el poder y para qué utilizan esos valores. Sin embargo, la relación de los valores con la Constitución y el ordenamiento jurídico en particular, forma parte de una interminable evolución del pensamiento humano, en especial de filósofos y juristas que dedicaron obras ${ }^{4}$ enteras a su análisis.

El estudio de los valores como categorías universales "es tan antiguo como la filosofía misma." Se trata de un tema que ha sido objeto de atención por generaciones en la sociedad. La polémica siempre existente sobre qué entender como bueno, justo, bello o útil, y qué aceptar como malo, injusto, feo o perjudicial, se ha dado en torno a interrogantes a los que el pensamiento humano ha buscado respuestas que le permitan guiarse en la vida. Fabelo ${ }^{6}$ explica que estas respuestas no siempre han sido analizadas de la misma forma, pues a las dudas y el desconocimiento ingenuo que muchos han tenido sobre el tema, se suman los diversos criterios encontrados entre individuos, grupos, clases o capas sociales, cada uno igualmente convencido de la autenticidad de sus respectivas concepciones de los valores, acordes con determinados contextos históricos e intereses socio-clasistas.

Las reflexiones del presente artículo tienen implicaciones para todo operador jurídico que se adentre en el estudio de la relevancia o no de los valores constitucionales, especialmente para la jurisprudencia que los interprete y aplique en la solución de casos en los que los tradicionales medios de interpretación no ofrecen una solución justa. Se responden interrogantes tales

4. Véase Alfredo Stern. LA Filosofía de los valores. Trad. Humberto Piñera-Llera. Minerva. (1944); Francesco Orestano. Los valores humanos. Trad. V. P. Quintero. Argos. (1947); José Ortega y Gasset. ¿QuÉ SON LOS VALORES? UNA INTRODUCCIÓN A La estimativa y España invertebrada. Obras Completas. Revolución de Occidente. (1946-1947); Rafael Rojina-Villegas. La Justicia, valor supremo del Derecho. Revista DE LA Escuela NACIONAL DE JURISPRUdencia 39 y 40. Tomo x. Julio-diciembre de 1948. Págs. 239- 254; Chaim Perelman. De la Justicia. Trad. Ricardo Guerra. Centro de Estudios Filosóficos. unAm, Dirección General de Publicaciones. (1964); Urbano Ferrer-Santos. Los valores en el ámbito jurídico. Persona y DeRecho: Revista DE FUNDamentaCión de las Instituciones JuRídicas y de Derechos Humanos 9. 1982. Págs. 93-102; Carlos Santiago Nino. Justicia. Doxa 14. 1993. Págs. 61-74.

5. Véase Julio Fausto Fernández. Los Valores y el Derecho. Ministerio de Cultura. (1957). Pág. 25.

6. Cf. José Ramón Fabelo-Corzo. Los valores y sus DEsafíos ACtuales. José Martí. (2003). Pág. 17. 
como si el reconocimiento de valores por las constituciones es producto del azar histórico, cuáles son las razones que han conllevado a que adquieran el apelativo de "superiores" o "supremos" del ordenamiento jurídico, si forman o no parte del derecho positivo, y si es suficiente con su reconocimiento constitucional para lograr su efectiva consecución y realización en la sociedad.

No obstante, en el propósito de llegar a estos entendimientos y al significado que actualmente tienen dichos valores, es imprescindible el desarrollo de una breve retrospectiva de las principales concepciones históricas en torno a los valores en el pensamiento iusfilosófico. Lo anterior sirve de base a cualquier intento de fundamentar el sentido de los valores que hoy en día enaltecen las páginas de numerosas constituciones, como es el caso de las iberoamericanas. Sobre todo, si se tiene en cuenta que la inclusión de valores en la Norma Suprema - fundamentalmente en aquellos procesos constituyentes democráticos-, supone la positivación de los fundamentos éticos, de la identidad y del patrimonio moral del pueblo en cuestión. Por tanto, en el presente artículo se propone una redefinición de los valores constitucionales, considerándolos como parte de la identidad y del patrimonio intangible de los pueblos, producto de pensamientos, de cultura e ideología, así como de condicionantes históricas, políticas, económicas y sociales.

\section{BREVE SISTEMATIZACIÓN DE LOS VALORES EN EL PENSAMIENTO IUSFILOSÓFICO: PRINCIPALES CONCEPCIONES HISTÓRICAS}

El amplio tratamiento de los valores en el pensamiento iusfilosófico mundial hace imposible reflejar todos los criterios y debates, si se tiene en cuenta que ya existen varios estudios dedicados al tema. Interrogantes tales como: ¿cuál es la naturaleza de los valores humanos en general?, ¿de dónde surgen?, o ¿cuál es su fuente?, han encontrado diferentes respuestas. Diversos sistemas, en un intento de proporcionar una explicación, ofrecen diversas interpretaciones de los valores en general. Estas posiciones podrían clasificarse en cuatro grupos principales, a saber: naturalista, objetivista, subjetivista y sociologista, ${ }^{7}$ cada una de las cuales ha desarrollado a su vez disímiles corrientes del pensamiento sobre el tema.

\footnotetext{
7. La clasificación fue tomada de José Ramón Fabelo-Corzo supra, nota 6. Pág. 18.
}

Una de las concepciones que tributa larga historia es la conocida como "naturalista", que tuvo en Demócrito $^{8}$ (460-370 a. C.) un clásico representante, para quien el bien, lo útil y lo bello es aquello que se corresponde con la naturaleza; y el mal, lo perjudicial y lo horrible son lo antinatural. Por su parte, en la postura sobre la justicia de Aristóteles (384-322 a. C.), ${ }^{9}$ se encuentra que el fundamento de validez de la ley humana radica en la ley natural, la cual a su vez se encuentra en la ley divina. Así, se entiende la relación legal y moral como subordinada a actos de prudencia, al enfatizar el principio de conocimiento exhaustivo de la naturaleza para alcanzarla: "lo equitativo, al ser justo, no es únicamente lo justo según la ley, sino un correctivo de la justicia legal". ${ }^{10}$ La concepción naturalista tuvo un amplio despliegue a partir del Renacimiento, vinculada a la visión optimista y a la fe en la razón. La Ilustración, y en particular el materialismo francés del siglo XVIII, fueron exponentes destacados de esta concepción. Los valores se asocian a la acción de las leyes naturales y, si en ocasiones los humanos no actúan en conformidad con ellas, se debe a su desconocimiento: "La causa de todos los infortunios y de todas las desgracias de los hombres consiste en la ignorancia", ${ }^{11}$ señaló Helvecio (17151771). La Ilustración trató de conducir a la solución de los problemas sociales y a la posibilidad del establecimiento de un contrato social. Como resultado se erigiría el Estado, y se definen las normativas y las leyes de convivencia que han de garantizar la realización de los intereses naturales de todos, y la consolidación de valores tales como la igualdad natural entre los hombres, los cuales, afirmó Rousseau (1712-1778), "pudiendo ser desiguales con fuerza o talento, vienen a ser todos iguales por convención y derecho". ${ }^{12}$

El paso del naturalismo ilustrado a las concepciones contemporáneas, sobre todo en su versión objetivista, fue mediado por la fuerte crítica que el filósofo alemán Kant (1724-1804) dirigiera contra aquel. A diferencia de los ilustrados, para Kant, ${ }^{13}$

\footnotetext{
8. Véase V. F. Asmus. Historia de la filosofía antigua. Pueblo y Educación. (1988). Págs. 119 y 120.

9. Véase Alicia Rendón-López. El otro triángulo de las Bermudas: el amor, la felicidad y la justicia social. Revista Amicus Curiae 1. Segunda Época 2. 2013. Pág. 4.

10. Véase Aristóteles. Ética a Nicómaco. Edición del Centro de Estudios Constitucionales. (1985). Pág. 86.

11. Véase I. S. Narski. La filosofía de Europa Occidental en EL SIGLO XVIII. Pueblo y Educación. (1985). Pág. 187.

12. Véase Jean Jaques Rousseau. El contrato social. 4a ed. UNAM, Instituto de Investigaciones Jurídicas. (1984). Pág. 32.

13. Véase Immanuel Kant. Crítica de la razón pura. Trad. Manuel G. Morente. Librería General de Victoriano Suárez. (1928). Disponible en: http://www.cervantesvirtual.com
} 
el ser humano es esencialmente egoísta y no está capacitado para realizar una conducta moralmente valiosa, mientras intente llevar a la práctica sus inclinaciones e intereses naturales, por lo que concibe al ser humano coexistiendo en dos mundos: el mundo del ser (realidad), y el mundo del deber ser (valor). Esta separación kantiana sirvió de fundamento para el desarrollo del objetivismo axiológico, el cual tuvo entre los neokantianos de la escuela sudoccidental alemana de Friburgo a sus iniciadores contemporáneos: Windelband (1848-1915) y Rickert (18631936). ${ }^{14}$ Estos vieron en Kant al gran descubridor de una nueva dimensión del mundo, el reino de los valores, al cual no llegan las ciencias naturales y en el que impera la libertad y no la necesidad natural. Los neokantianos suponen que los valores han de constituirse en el verdadero objeto de la filosofía, al dejar a la ciencia natural todo lo que tenga que ver con las relaciones causa-efecto; esto convierte a los valores en una especie de principios a priori que poseen la fuerza de una ley objetiva, aunque no sean alcanzables por la racionalidad científica. Esta línea condujo a una separación entre las ciencias naturales y las denominadas "ciencias de la cultura". 15

La tendencia continúa desarrollándose, pero encuentra sus representantes más difundidos en Scheler $(1874-1928)^{16}$ y Hartmann $(1882-1950),{ }^{17}$ quienes despliegan toda una teoría por medio de sus concepciones fenomenológicas. Sin embargo, se considera a Husserl (1859-1938) ${ }^{18}$ como el fundador de la fenomenología, cuyo pensamiento tiene origen kantiano, pero pronto se separa del dualismo de Kant para desbordar las posiciones del idealismo subjetivo. ${ }^{19}$ De acuerdo con Scheler, ${ }^{20}$ los valores son cualidades de orden especial que descansan en sí mismos y se justifican por su contenido. El sentimiento de valor es una capacidad del hombre que le permite captar los valores, lo que concuerda con Kant en no fundar la ética en la experiencia del mundo real,

14. Véase José Ramón Fabelo-Corzo, supra, nota 6. Pág. 22.

15. Cf. Henrich Rickert. Ciencia cultural y Ciencia natural. Espasa-Calpe S. A. (1937). Págs. 160 y 161.

16. Véase Max Scheler. Ética. Nuevo ensayo de fundamentaCión DE Un PERSONAlismo ÉTico. Trad. Hilario Rodríguez-Sanz. Caparrós. (2001).

17. Puede consultarse el resumen de su doctrina en Luciano Parejo-Alfonso. Constitución y LOS VAlORES DEL ORDENAmiento. Centro de Estudios Ramón Areces S. A. (1990). Págs. 47-48.

18. Véase Edmund Husserl. Investigaciones LóGICAs. Trad. Manuel García Morente y José Gaos. Alianza. (2001).

19. Véase Julio Fernández-Bulté. Filosofía del Derecho. Félix Varela. (2005). Págs. 226 y 227.

20. Véase Luciano Parejo-Alfonso, supra, nota 17. Pág. 46. sino en valores dados a priori. A diferencia de él, los valores son, en sentido aristotélico, materiales y no formales; es decir, constituyen esencias irracionales, alcanzables por la vía de la intuición emocional y no por la razón. Por su parte, Hartmann ${ }^{21}$ considera los valores como ideas en sentido platónico, susceptibles de ser conocidos a priori de forma emocional y no reflexiva, por medio de la emoción valorativa. Los dos pensadores conciben los valores como dados de una vez y para siempre, eternos, inmutables, ordenados en cierta jerarquía también inamovible. ${ }^{22}$

Recaséns-Siches (1903-1977) ${ }^{23}$ toma como base de su pensamiento jurídico la filosofía de los valores de Scheler y Hartmann. Sin embargo, su estimativa jurídica - la cual considera como aquella parte de la filosofía del derecho que estudia los valores-, supone un intento de superar el objetivismo axiológico de los dos alemanes, de los que realiza una cierta crítica, además de procurar matizar la distinción entre realidad y valor. Una vez demostrado que los valores son el criterio para juzgar la validez intrínseca del orden jurídico y que constituyen el objeto de la estimativa jurídica, Recaséns-Siches ${ }^{24}$ plantea los siguientes problemas para el desarrollo de esta disciplina: determinar si el conocimiento de los valores es a priori o empírico; de ser a priori, determinar si su naturaleza es subjetiva u objetiva; el modo concreto en que los valores se realizan en la historia (la realidad); cuáles son los valores propios del derecho; y analizar el valor de justicia y su relación con el resto de los valores del derecho. $^{25}$

Tiempo atrás otros pensadores desarrollaron la filosofía jurídica de los valores, cuyos aspectos más importantes se aprecian en el Renacimiento: desde el idealismo, a la cuestión del valor. Stammler (1856-1938) - neokantiano que reacciona frente al positivismo y al materialismo - inicia con su obra

\footnotetext{
21. Id. Págs. 47-48.

22. Cf. José Ramón Fabelo-Corzo, supra, nota 6. Pág. 22.

23. Véase Luis Recaséns-Siches. Tratado general DE FILOSofía DeL DERECHO. $15^{\mathrm{a}}$ ed. Porrúa. (2001).

24. Véase Carlos de la Torre-Martínez. LA RECEPCión DE LA FILOSOFÍA DE LOS VALORES EN LA FILOSOFÍA DEL DERECHO. UNAM, Instituto de Investigaciones Jurídicas. (2005). Pág. 280.

25. "Recasens plantea como tarea futura de la Estimativa Jurídica la determinación de los valores jurídicos y de su jerarquía, sí afirma que entre los valores supremos que deban inspirar el Derecho se han de encontrar la dignidad moral del hombre, la libertad como esfera de autonomía, y la paridad fundamental ante el Derecho". Véase Francisco Javier Díaz-Revorio. Sobre los valores en la Filosofía Jurídica y en el Derecho Constitucional. Revista BRASILEIRA DE Direito Constitucional- RbDC 19. Enero/junio de 2012. Pág. 23.
} 
una corriente: el idealismo jurídico; ${ }^{26}$ sostuvo que no basta conocer qué es el derecho, sino que es imprescindible arribar a la verdad de qué debe ser para que alcance las exigencias de la justicia, planteándose un propósito deontológico. ${ }^{27}$ Como consecuencia de su pensamiento, se inicia una dirección logicista de la reflexión filosófico-jurídica, la cual culminó en la escuela de Viena, fundada y encabezada por Kelsen ${ }^{28}$ (1881-1973), para quien el derecho debe dedicarse esencialmente al estudio de las normas - a partir de las cuales debe derivar sus conceptos jurídicos-, y estas normas son las del derecho positivo. Stammler dedicó varias reflexiones a la justicia. ${ }^{29}$ Para Kelsen:

El valor es un concepto derivado del concepto de norma, ya que son las normas las que constituyen los valores. En su opinión, los valores se reducen a la relación identificada entre el objeto dado (conducta) y la norma. En el caso de valor positivo se trata de una relación de «ser conforme con» la norma y en caso de valor negativo la relación es de no conformidad con la norma. ${ }^{30}$

Entre las direcciones que reaccionaron contra el vacío normativista se encuentra la escuela del derecho libre, cuyo principal exponente en Francia fue Geny. ${ }^{31}$ Este defendió - con una notable influencia stammleriana- que debía dejarse a los jueces un total arbitrio dentro del cual pudieran resolver los litigios, sin atenerse a sus caprichos u opiniones personales, sino al criterio que les dictaran los fines generales de la sociedad. La superación del normativismo kelseniano, desde un riguroso punto de vista ontológico, no vino de las grandes urbes europeas. Cupo a la escuela egológica y a su fundador, el argentino Cossío (1903-1987), en torno a la polémica sostenida

26. Véase Karl Larenz. LA FILOSOfíA CONTEMPORÁNEA DEL Derecho y del Estado. Trad. Eustaquio Galán Galán-Gutiérrez y Antonio Truyol Truyol-Serra. Revista de Derecho Privado de 1942. Págs. 47 y ss.

27. Cf. Julio Fernández-Bulté, supra, nota 19. Pág. 217.

28. Sobre la teoría pura del derecho y, en general, las tesis de Kelsen y la escuela a él vinculada, véase Luis Recasens-Siches. DiRECCIONES CONTEMPORÁNEAS DEL PENSAMIENTO JURÍDICO. Labor. (1929). Págs. 14 y ss. También pueden consultarse directamente sus criterios en Hans Kelsen. Teoría PURA DEL DERECHO. Trad. de la $2^{\text {a }}$ ed. en alemán por Roberto J. Vernengo. UNAM, Instituto de Investigaciones Jurídicas. México. (1982).

29. Véase Hans Kelsen. ¿QuÉ es LA Justicia? Trad. Leonor Calvera. Ediciones elaleph.com. (2000). Págs. 5 y 83.

30. Véase Andrzej Grabowski. Clasificar valores en el Derecho. Sobre la concepción de Manuel Atienza y Juan Ruiz Manero. DoxA 20. 1997. Pág. 443.

31. Véase Julio Fernández Bulté, supra, nota 19. Pág. 222. con Kelsen desde 1941, al enfatizar que el derecho es regulador y plasmador de conductas. Uno de sus aportes a toda la iusfilosofía es su apreciación de la axiología como inmanente al derecho, a la que dedicó reflexiones sobre valores jurídicos tales como orden, seguridad, paz, poder, cooperación, solidaridad y justicia. ${ }^{32}$

Una aplicación al campo jurídico de la filosofía de la cultura se observó en la obra de Lask, quien refiriéndose al problema del valor jurídico como entidad autónoma o no, analiza dos corrientes, de modo que para una no hay más valores que los individuales, mientras que para la otra, junto a estos existen, con entidad propia, valores sociales, objetivos o supraindividuales. Se inspiraron en su obra Münch y Mayer (1875-1924), quienes consideraban que los ideales o valores jurídicos vienen a ser una parte más de los ideales o valores culturales generales. En el marco del culturalismo generado por esta escuela alemana, varios autores concentran sus esfuerzos en determinar y fundamentar el contenido de los valores culturales y, en concreto, jurídicos. ${ }^{33}$ Sin embargo, aunque coinciden en ese esfuerzo, divergen en su concepción acerca de la cultura, como, por ejemplo, Radbruch ${ }^{34}$ (1878-1950), considerado uno de los pensadores de la fenomenología jurídica. Este autor, influido por ella conviene en que la cultura es una realidad referida a valores y que el derecho es una parte específica de la cultura. Respecto a los valores, sostuvo que "el Bien común, justicia, seguridad jurídica, son considerados los fines supremos del derecho, pero no en una hermosa armonía, sino en aguda lucha el uno con el otro". ${ }^{35}$

Otro pensamiento jurídico desarrollado fue la denominada "jurisprudencia valorativa". Esta escuela está representada, entre otros, por varios de los autores ya citados (Windelband, Rickert, Mayer y Radbruch). Parte de la consideración según la cual la metodología jurídica es esencialmente teleológica, de manera que el derecho es la realidad que tiene el objetivo de servir a la justicia, valor que permite su formulación conceptual. Aborda la problemática del derecho desde la perspectiva de la teoría de los valores jurídicos, desde una investigación fenomenológica que permita dar con los principios y con los fines del derecho. Su objetivo es fundamentar la ciencia

\footnotetext{
32. Véase Carlos Cossío. Los valores jurídicos. ANUARIO DE Filosofía del Derecho 4. 1956. Págs. 27-92.

33. Puede consultarse un resumen de la doctrina de estos autores en Luciano Parejo-Alfonso, supra, nota 17. Págs. 86 y ss.

34. Véase Julio Fernández-Bulté, supra, nota 19. Pág. 229.

35. Véase Gustav Radbruch. El HOMBre EN EL DERECHO. Depalma. (1980). Pág. 103.
} 
jurídica por su referencia a los valores. Sus defensores sostienen que la clave para la interpretación de las normas jurídicas no consiste en aclarar su significación literal, ni en explicarlas como manifestaciones de una voluntad, sino de acuerdo con su sentido, al investigar sus fuerzas vitales creadoras a las que convierten en valores con referencia a la justicia. Como esto no pueden llevarlo a cabo las leyes en toda su amplitud, la interpretación se supera en la acción jurídicamente creadora del juez. ${ }^{36}$

En oposición al objetivismo axiológico, se desarrolla la línea subjetivista. Esta concepción ubica la fuente de los valores en el sujeto, en sus sentimientos, gustos, aspiraciones, deseos o intereses. Brentano (1838-1917) es considerado por algunos autores ${ }^{37}$ como el precursor en la filosofía moderna de la teorización de los valores. Al rechazar el idealismo kantiano y hegeliano, retorna al punto de vista empírico del aristotelismo, e impugna la vía intelectual para el conocimiento de los valores, en cuya objetividad no cree, al afirmar el carácter emocional de los juicios de valor. Su camino lo continúan sus discípulos Von Meinong (1853-1920) y Von Ehrenfels (1859-1932). Ambos $^{38}$ sostuvieron una famosa polémica, en la cual la discrepancia fundamental radicaba en el aspecto de la subjetividad que da validez al valor: de acuerdo con Meinong, el placer o el agrado; para Ehrenfels, el deseo. Muchos continuaron la línea de pensamiento subjetivista, adscritos a diferentes concepciones filosóficas. El neorrealista Barton Perry ${ }^{39}$ (1876-1957), el empirista lógico Russell (1872-1970), y desde un ámbito existencialista Sartre (1905-1980). Russell ${ }^{40}$ estimaba que el asunto de los valores está fuera del dominio del conocimiento. Sartre ${ }^{41}$ afirmó que los

36. Véase Bartolo Pablo Rodríguez-Cepeda. Metodología juríDICA. $7^{a}$ reimpresión. Oxford University Press. (2006). Págs. 179 y 180.

37. "Si bien todos los autores están de acuerdo en que la axiología data apenas de las postrimerías del siglo XIX, no hay unanimidad en cuanto a su origen próximo. Unos como lo hemos hecho nosotros, señalan a Brentano, otros a Lotze (1817-1881), hay quienes a Juan Federico Herbat (1776-1841), y los hay quienes señalan a otros filósofos de menos nombradía como creadores de la teoría general de los valores, como Carlos Bohem (1846-1911), o Federico Eduardo Beneke (1798-1854)." Véase Julio Fausto Fernández, supra, nota 5. Págs. 31 y 32 .

38. Id. Pág. 58 .

39. El neorrealista Barton Perry, al tiempo que niega la posibilidad de un conocimiento a priori, opina que algo es valioso cuando es objeto de un interés; y también a la inversa: "lo que es objeto de interés es, ipso facto, valioso". Véase José Ramón Fabelo-Corzo, supra, nota 6. Pág. 24.

40. Véase Bertrand Russell. Religión y Ciencia. Fondo de Cultura Económica. (1956). Pág. 162.

41. Véase José Ramón Fabelo-Corzo, supra, nota 6. Pág. 24. valores están exentos de cualquier criterio objetivo. El hombre es su única fuente, criterio y fin; no la sociedad, ni el hombre en general, sino cada individuo particular, cada "yo".

Una dirección que se despliega en el terreno filosófico de los valores la constituye la reacción frente al objetivismo valorativo: la escuela de Uppsala. Su principal exponente, Hägerströms, destaca la relación entre valores e intereses sociales. Otra de las variantes desarrolladas dentro del subjetivismo es la fundamentación psicológica de la función valorativa y la especificidad de la argumentación moral: el emotivismo. Stevenson (1908-1979) ${ }^{42}$ señaló que los juicios de valor tienen, junto con la naturaleza cognoscitiva, una función específica de naturaleza emocional, y cómo dichos juicios pueden ser justificados; desarrolló toda una teoría de la argumentación moral. En otro orden, también adquirió desarrollo el enfoque subjetivista con el resurgimiento del neoliberalismo. Basándose en el conflicto individuo-sociedad, sitúa en divergencia conceptos tales como libertad e igualdad. Defiende la concepción según la cual no existen valores absolutos y definitivos que puedan servir de criterios para la conducta humana, y que releven al hombre de su responsabilidad de decidir libremente en cada caso. Para von Hayek ${ }^{43}$ (1899-1992), la sociedad y la civilización son resultado de un orden determinado de libertades individuales, de cuya permanencia depende la garantía de estas, y en el que lo importante es la esfera de la libertad personal.

Por otra parte, se imponen algunas alusiones en torno a posiciones sociologistas que, así como las anteriores, han intentado explicar los valores. En este sentido, se encuentran autores tales como Lévy Bruhl (1857-1939), Durkheim (1858-1917) y Bouglé (18701940). Según esta concepción, ${ }^{44}$ es valioso lo que la sociedad considera como tal. Los valores son el resultado de ciertas convenciones sociales que presuponen el apoyo de la mayoría, y se promueven y reproducen por medio de la cultura y las tradiciones, al actuar como entidades objetivas con fuerza imperativa. Así, cada nueva generación se encuentra con un mundo de valores ya creado, convertido en normas morales, preceptos religiosos, ideales estéticos o leyes, del que se apropia por medio de la educación y que le permite integrarse a la identidad colectiva. La mayoría de estos autores no solo concibieron una manera

\footnotetext{
42. Véase Julián Marías. Historia DE LA filosofía. Alianza Universidad. (1986). Págs. 367 y ss.

43. Véase Friedrich August von Hayek. Derecho, Legislación y LIBERTAD. NORMAS Y ORDEN. VOL. I. Unión Editorial. (1978).

44. Véase José Ramón Fabelo-Corzo, supra, nota 6. Págs. 24 y 25.
} 
distinta de entender los valores, la forma y los métodos específicos de investigarlos, sino que emprendieron ellos mismos importantes estudios sobre los valores en diferentes comunidades. Sin embargo, Fabelo-Corzo ${ }^{45}$ explica cómo quedan algunos interrogantes que el sociologismo no llega a responder: ¿no existe la posibilidad de valoraciones colectivas erradas? ¿Cómo solucionar un conflicto valorativo internacional si las valoraciones contendientes tienen el apoyo consensuado de sus respectivas culturas? ¿Podría justificarse axiológicamente el nazismo por el apoyo mayoritario del pueblo alemán? ¿Es superior el valor estético de un libro por ser el preferido y el más leído? ¿Cómo se determina la opinión de la mayoría, acaso esta no puede ser objeto de manipulación? ¿Cómo justificar las transformaciones o revoluciones sociales que intentan cambiar el sistema de valores imperantes y que muchas veces parten de los criterios valorativos de minorías rebeldes? Al partir, como criterio último de los valores, de la conciencia colectiva, el sociologismo queda incapacitado para responder estas preguntas.

Por otra parte, construcciones que enmarcan el debate de superación de la antinomia tradicional entre iusnaturalismo y positivismo son las de Hart, Bobbio y Frondizi. Hart ${ }^{46}$ (1907-1992) reconoce la influencia de la moral sobre el derecho. Explica que la decisión judicial, especialmente en materias de elevada importancia constitucional, a menudo implica una elección entre valores morales, y no meramente la aplicación de algún principio moral aislado. El juez puede hacer una elección que no es arbitraria ni mecánica, y desplegar las virtudes judiciales características de la decisión jurídica: imparcialidad y neutralidad al examinar las alternativas, consideración de los intereses de todos los afectados, así como una preocupación por desarrollar algún principio general aceptable como base razonada de la decisión. Sostiene cómo ya que es siempre posible una pluralidad de tales principios, es indudable que no se puede demostrar que una decisión es la única correcta, pero es posible conseguir que se acepte como el producto razonado de una elección imparcial bien informada, al aparecer la "ponderación" y el "balance" característicos del esfuerzo por hacer justicia en medio de intereses en conflicto.

\footnotetext{
45. Id. Pág. 28.

46. Véase Herbert Lionel Adolphus Hart. El Concepto DE Derecho (The Concept of Law). Trad. Genaro R. Carrió. Abeledo-Perrot s. A. (1998). Págs. 251-253.
}

En Bobbio (1909-2004), ${ }^{47}$ la filosofía jurídica es cabalmente y ante todo teoría de la justicia, de los valores:

El fundamento de derechos, de los que se sabe solamente que son condiciones para la realización de valores últimos, es la llamada a estos valores últimos, los cuales no se justifican, se asumen, y son además, antinómicos, no pueden realizarse todos a la vez. Para realizarlos se necesitan concesiones entre las partes que requiere recíprocas renuncias, entran en juego las preferencias personales, las elecciones políticas, las orientaciones ideológicas. ${ }^{48}$

Bobbio dedicó varios análisis a la libertad y a la igualdad, ${ }^{49}$ así como a la relación entre la política y el derecho. Respecto a la norma jurídica, explicó que si se quiere establecer una teoría sobre bases sólidas, hay que tener en cuenta si puede ser sometida a tres distintas valoraciones: justicia, validez y eficacia.

Frondizi $^{50}$ (1910-1983) se propuso elaborar una concepción axiológica que superara los extremos representados por el subjetivismo y el positivismo, de manera que logró una importante difusión de sus ideas en el contexto latinoamericano. Sostuvo que, ante cualquier conflicto entre normas, debe elegirse aquella que esté sustentada por el valor superior, al plantearse el interrogante: $\mathrm{Si}$ el valor ha de sustentar a la norma, ¿qué es lo que fundamenta al valor? Al filósofo no le satisface la respuesta que ofrecen el objetivismo, el subjetivismo y el sociologismo, por lo que intenta tomar una vía distinta: el valor surge en la relación sujeto, objeto y valoración; al ser estos para él los componentes del valor, este, por lo tanto, posee una cara objetiva y otra subjetiva. Explica el carácter situacional y cambiante de los valores, su naturaleza compleja, así como el vínculo que se establece entre las normas éticas y los valores como su fundamento. Sin embargo, opina Fabelo-Corzo, ${ }^{51}$ a pesar de la loable intención de Frondizi de superar las limitaciones de estas corrientes, no puede decirse que lo logre totalmente, sobre todo en lo referido al subjetivismo.

\footnotetext{
47. Véase Norberto Bobbio. Teoría General del Derecho. Temis. (1987). Pág. 20.

48. Véase Norberto Bobbio. El tiempo De los Derechos. Trad. Rafael de Asís Roig. Editorial Sistema. (1991). Págs. 56, 64 y 65.

49. Cf. Norberto Bobbio. Igualdad y Libertad. Ediciones Paidós Ibérica S. A., I. C. E./U. A. B. (1993).

50. Véase Risieri Frondizi. Pensamiento axiológico. AntoLogía. Instituto Cubano del Libro-Universidad del Valle. (1993); y Risieri Frondizi. ¿QUé son los valores? Fondo de Cultura Económica. (1994).

51. Véase José Ramón Fabelo-Corzo, supra, nota 6. Págs. 32-34.
} 
Por otra parte, el liberalismo de Rawls (19212002) aparece corregido por la idea de la prevalencia de la justicia como límite, desde la imparcialidad racional al libre juego social que opera desde las instituciones sociales productoras de una sociedad bien ordenada, al propugnar al Estado como instrumento neutro al servicio de la verdad y de lo justo. ${ }^{52}$ FabeloCorzo $^{53}$ plantea que su teoría de la justicia no está dirigida a la eliminación de las grandes desigualdades sociales, sino a su ordenamiento, de manera que estas "no sean mayores de lo necesario para que redunden en provecho de los menos favorecidos y el esquema de iguales libertades democráticas no se vea afectado de forma adversa" ${ }^{54}$ Con base en las aportaciones de Rawls, Dworkin (1931-2013) ${ }^{55}$ formula una teoría del derecho en la que la base axiológica la constituyen los derechos individuales, especialmente el de igual consideración y respeto. Mantiene las distancias con la filosofía utilitarista liberal, y critica el positivismo, a partir de cómo en la práctica judicial no se cumple la tajante separación entre moral y derecho. Dworkin crítica a Hart por reducir el derecho a un sistema de reglas, e ignorar la importancia de los principios como fuentes del derecho (estas críticas en su momento fueron respondidas por Hart). ${ }^{56}$

Dworkin $^{57}$ destaca la dimensión del peso o importancia de los principios y directrices en las decisiones judiciales, incluso de aquellos que no están normados $y$, sin embargo, los enseñan los profesores de derecho, los citan los textos, los celebran los historiadores del derecho o los acepta la comunidad;

52. Véase John Rawls. Teoría de la justicia. Trad. María D. Domínguez. Fondo de Cultura Económica. (1979). Págs. 340-341. También puede consultarse las respuestas que da a las críticas recibidas de su teoría en John Rawls. LA JUSTICIA COMO EQUIDAD. UNA reformulación. Trad. Andrés de Francisco. Paidós. (2002).

53. Véase José Ramón Fabelo-Corzo, supra, nota 6. Pág. 127.

54. Véase John Rawls. Justicia COMO EQUidad. Materiales PARA UnA TeOría de la justicia. Tecnos. (1986). Pág. 16.

55. Véase Ronald Dworkin. Los DeREChos EN SERIO. $1^{\text {a }}$ ed. Trad. Marta Guastavino. Ariel s. A. (1984). Págs. 9, 10, 13, 14 y 23.

56. "Mi teoría no es una teoría del positivismo de meros hechos, puesto que entre los criterios [para determinar] el derecho admite valores, no meros hechos (...) Al imputarme un positivismo de "meros hechos" en Law's Empire, Dworkin ignora este aspecto de mi teoría (...) ignora mi aceptación explícita de que la regla de reconocimiento puede incorporar como criterios de validez jurídica la conformidad con principios morales o valores sustantivos; por lo que mi doctrina es lo que se ha denominado "positivismo suave" y no, en la versión que Dworkin tiene de ella, positivismo de meros hechos". Véase Herbert Lionel Adolphus Hart. Post Scríptum al Concepto del Derecho. Trad. Rolando Tamayo y Salmorán. UNAM, Instituto de Investigaciones Jurídicas. (2000). Págs. 22, 23 y 26.

57. Véase Ronald Dworkin, supra, nota 57. Págs. 15, 81 y 99. principios que el tribunal cita en sus fallos y justifican la adopción de una norma nueva. Sostiene que los principios son dinámicos y cambian con gran rapidez, y todo intento de canonizarlos está condenado al fracaso. Por esta razón, alega que su aplicación no es automática, sino que exige el razonamiento judicial y la integración del razonamiento en una teoría coherente. Cuando es posible que se construyan teorías que justifiquen respuestas distintas, recomienda acoger la teoría que explique mejor el derecho histórico y el derecho vigente. Por lo que el juez, ante un caso difícil, debe balancear los principios y decidirse por el que tiene más peso, teniendo en cuenta la integridad del derecho. En este sentido, propone un nuevo modelo de la función judicial (el modelo de la respuesta correcta en los casos difíciles), a partir de cómo en los casos en los que las normas positivas no ofrezcan una solución, los jueces deben hallar dicha solución en el derecho preestablecido, no en virtud de su discreción (según sostiene el positivismo), sino por medio de un razonamiento capaz de encontrar la respuesta correcta a la situación dada, y proponer un modelo de juez omnisciente: el célebre Hércules. ${ }^{58}$ Así, considera que los jueces no basan sus decisiones en objetivos sociales o directrices políticas, sino que deben resolver los casos difíciles con base en principios que fundamentan derechos, e identificar una concepción particular de la moralidad comunitaria como decisiva para los problemas jurídicos. ${ }^{59}$ Por tanto, alega que el juez carece de discreción y de poder político, de manera que en su modelo, el juez es garantizador de derechos individuales y no creador de ellos.

Una de las críticas que ha recibido es que "Dworkin, como Rawls, cree que ningún objetivo social se puede justificar -incluso si sirve al bienestar general- si viola derechos individuales". ${ }^{60}$ Esto tiene que ver con que su filosofía jurídica, al estar fundamentada en los derechos individuales ${ }^{61}$ y considerarlos - especialmente el derecho a la igualdad, consideración y respeto-, como triunfos frente a

58. Véase Ronald Dworkin. El IMPERIO de la JUSTICIA. 2a ed. Trad. Claudia Ferrari. Editorial Gedisa s. A. (1992). Pág. 171.

59. Véase Ronald Dworkin, supra, nota 57. Págs. 16, 202 y 203. 60. Id. Pág. 23.

61. "No sabe Dworkin, o no lo incluye por lo menos, que una buena teoría y filosofía de los derechos humanos, con sus tres generaciones bien orquestadas como cualidad estructural del ser humano pudieron haberle ayudado mucho mejor. Los derechos individuales no pueden pensarse sin los sociales y mucho menos sin los de solidaridad. Para que haya unos tiene que haber los otros." Véase Miguel Eduardo Morales-Lizárraga. La controversia Hart-Dworkin en torno a la decisión judicial. Revista Amicus Curiae 2(3). Segunda Época. 2013. Pág. 10. 
la mayoría, estima que ninguna directriz política ni objetivo social colectivo puede triunfar frente a un auténtico derecho (esto conlleva a que muchos tilden su filosofía política como individualista). No obstante, es válido destacar que sus reflexiones se basaron en el análisis de decisiones políticas en comunidades en las que la justificación colectiva general es utilitarista, y las ilustra con ejemplos del contexto norteamericano. Como parte de la respuesta a estas críticas, sostuvo que la teoría de los derechos que presentó:

No niega que algunos derechos sean más importantes que otros. Ningún supuesto derecho es tal (desde mi punto de vista) a menos que invalide por lo menos un caso marginal de una justificación colectiva general; pero un derecho es más importante que otro si alguna justificación colectiva especialmente dramática o urgente, que supere ese umbral, es capaz de anular al segundo, pero no al primero. ${ }^{62}$

De sus respuestas a las críticas, puede percibirse que su defensa de los derechos como triunfos sobre alguna justificación básica que apela al bienestar colectivo, tiene que ver, fundamentalmente, con los derechos políticos particulares, en atención a los contextos utilitaristas en los que circunscribió sus análisis. Respecto a su proposición de un juez Hércules, alude a un tipo de individuo que es erudito, sabio, conocedor del contenido del sistema jurídico y que, como tal, encontrará siempre la respuesta correcta. Sin embargo, se trata de un juez ideal que por las características que apunta de este, no ilustra lo que es la realidad de la preparación de los jueces y la impartición de justicia a nivel mundial. Además, absolutizó el hecho de la existencia única de una solución e interpretación correcta. Al afirmar que, en los casos difíciles, los jueces no basan sus decisiones en objetivos sociales o directrices políticas, pasa por alto que la historia de la humanidad ha demostrado que los jueces no se encuentran ajenos a aquellas. Su rechazo a la discrecionalidad judicial es otra de las cuestiones que ha encontrado fuertes críticas. No se percata de cómo incluso cuando el juez, en los casos difíciles, a fin de llegar a una "única respuesta correcta" y aplicar principios por su peso e importancia, lo hace al elegir, de manera discrecional, entre el conjunto de ellos que fundamenten mejor los derechos involucrados.

Pese a las críticas recibidas, es necesario reconocer que entre sus aportes se encuentra contribuir a la comprensión de qué es el derecho (al introducir principios y directrices a su concepto) y cómo pueden

62. Véase Ronald Dworkin, supra, nota 57. Págs. 493 y 494. aplicarlos los jueces en la solución de casos concretos, especialmente en casos difíciles. Sus concepciones como la de la integridad del derecho, la interpretación, los valores de la democracia, su método constructivo, la búsqueda de la racionalidad, del juez Hércules, entre otras-, han sido útiles para describir, criticar y proponer soluciones a problemas no solo jurídicos, sino también políticos, económicos y sociales.

Por último, ha cobrado interés una visión tridimensional del derecho, ${ }^{63}$ a la hora de enfrentar su definición y conocimiento, la cual propugna una visión integral en la que se consideren los tres aspectos que conforman el fenómeno jurídico: la norma, el hecho y el valor. Así, propone enfocar el derecho con una perspectiva realista y total, a partir de la observación del mundo jurídico de las normas, de las conductas sociales y de los valores. Con el propósito de superar explicaciones unilaterales o sectorizadas, sus seguidores rechazan que el derecho se reduzca a un empirismo sociológico o a pura normatividad. Afirman que no es puro hecho ni pura norma, sino un hecho social con forma normativa, de acuerdo con un cierto orden de valores, por lo que el derecho manifiesta una integración incesante de estos. Para estos autores, valorar es normar el mundo práctico, atendiendo el dinamismo humano y los fines de la vida social, por lo que el concepto de norma es posterior al de valor; este, como productor de normas, determina lo que debe ser y lo que no debe ser. Como representantes de esta escuela, se encuentran Lask, Reale, Legaz y Lacambra, García-Máynez y Recaséns-Siches. ${ }^{64}$

Rodríguez-Cepeda ${ }^{65}$ afirma que el derecho es una realidad compleja que presenta estas tres dimensiones íntimas y necesariamente vinculadas, como un campo de estudio que debe abordarse con espíritu crítico, a fin de captar la realidad jurídica de un modo integral. El autor explica que, para integrar la realidad total viva del derecho, deben abordarse dimensiones axiológicas y ontológicas de naturaleza jurídica. Otros autores ${ }^{66}$ sostienen que, en efecto, el derecho no solo es un producto del fenómeno social,

63. Se la denomina también "teoría trialista del derecho", nombre que por incluir el prefijo latino tri-, que significa "tres", hace también referencia a las tres "dimensiones" o "elementos" que, según esta teoría, tiene el derecho. $C f$. Abelardo Torré. InTroducción AL Derecho. 14a ed. Abeledo-Perrot. (2003). Pág. 501.

64. Véase Bartolo Pablo Rodríguez-Cepeda, supra, nota 38. Págs. 187 y 188.

65. Id. Pág. 114

66. Véase María Teresa Vizcaíno-López. InTroducción AL Estudio del Derecho. Ediciones de la Facultad de Derecho y Ciencias Sociales de la Universidad Michoacana de San Nicolás de Hidalgo. (2009). Pág. 33. 
ni tampoco solo un conjunto de normas que tienden a regular su conducta, también es un valor en sí mismo que tiende a proteger otros valores de suma importancia para la sociedad. De esta manera, el derecho se estudia desde el punto de vista axiológico.

\section{LA IMPORTANCIA DEL PENSAMIENTO IUSFILOSÓFICO EN LA CONCEPCIÓN DE LOS VALORES CONSTITUCIONALES}

La resumida referencia realizada a las cuatro concepciones históricas en torno al estudio de los valores denota cómo estos, "o son propiedades naturales, o son esencias ideales objetivas, o son el resultado de la subjetividad individual o bien colectiva". ${ }^{67}$ Enfrentar un análisis de los autores que de una u otra forma efectuaron sus estudios sobre los valores exige partir, ante todo, del momento histórico en que vivieron, para así comprender el sentido dado, sumado a los intereses socio-clasistas que mediaron en sus desarrollos teóricos.

Una de las principales aportaciones del pensamiento iusfilosófico sobre los valores ha sido la de reflexionar si estos constituyen criterios a los cuales el derecho debe orientarse. En efecto, los valores, además de dotar de fundamento material al orden jurídico, operan para juzgar la validez material de las normas, al ser pautas que orientan la creación, interpretación y aplicación del derecho. Todo intento de comprender el fenómeno jurídico en sus múltiples manifestaciones tiene necesariamente que tomar en cuenta y asignar una importancia de primer orden a la dimensión axiológica. ${ }^{68}$ Así:

La reflexión de la Filosofía jurídica y política, de la historia de las ideas, de la filosofía moral, de la historia del Derecho o del Derecho Constitucional, ha aportado suficientes elementos para identificar ese núcleo central de sentido de los valores, que los operadores jurídicos deberán tener en cuenta en su interpretación. ${ }^{69}$

Las concepciones sumariamente tratadas de los diferentes autores sobre los valores, cuyos puntos de vista han sido irreconciliables y a veces entroncados, no han impedido que el tema tenga hoy más interés

67. Véase José Ramón Fabelo-Corzo, supra, nota 6. Pág. 35.

68. Cf. Carlos de la Torre-Martínez, supra, nota 24. Págs. 311-320.

69. Véase Gregorio Peces-Barba Martínez. Los valores superiores. Anuario de Filosofía del Derecho 4. 1987. Págs. 385 y 386. que nunca, no solo desde el punto de vista de la filosofía, sino por sus implicaciones para el derecho, y dentro de este, para la práctica judicial. De esta manera, actualmente la difusión y el realce de los valores plasmados en las constituciones, resulta uno de los temas recurrentes para el nuevo constitucionalismo. Díaz-Revorio ${ }^{70}$ plantea que la mención constitucional a los valores parece evocar casi espontáneamente la denominada "filosofía de los valores", pero más allá de esta asociación de ideas, las distintas doctrinas procedentes de la filosofía y la política tienen utilidad para el derecho constitucional, ya que pueden ayudar a entender el fundamento y significado de los valores constitucionales.

Fabelo-Corzo ${ }^{71}$ sostiene cómo, dado que son los seres humanos los que formulan, aprueban y ejecutan las leyes $y$, para hacerlo, no pueden prescindir de sus intereses, anhelos y pasiones, el derecho ha intentado legitimarse y validarse apelando a valores. Por lo tanto, se pregunta qué debe hacer la filosofía, y particularmente la axiología, ante la multitud de usos del concepto de valor. Esto no significa que las ciencias dejen de usar el concepto en cuestión, pero sí que conozcan los límites de su uso dentro de tal acepción específica. Es tarea de la filosofía construir el aparato conceptual adecuado, en el cual encuentren expresión diferenciada los distintos usos del concepto valor. Se trata no de mantener un único concepto e insertar dentro de él los más diversos contenidos, sino de encontrar el concepto adecuado para cada uso concreto.

El citado autor propone que toda concepción de los valores implica tres planos o dimensiones: objetiva, subjetiva e instituida. Desde el punto de vista objetivo, es necesario entender los valores como parte constitutiva de la realidad social, como una relación de significación entre los distintos procesos o acontecimientos de la vida social y las necesidades e intereses de la sociedad en su conjunto. Este plano está dado por la relación funcional del objeto o fenómeno dado con el ser humano, lo que no significa que sea inmutable, sino por el contrario, dinámico y cambiante, atiende a condiciones histórico-concretas. Es posible que lo que hoy o aquí es valioso, mañana o allá no lo sea, por haber cambiado la relación funcional del objeto en cuestión con lo humano. El segundo plano se refiere a la forma en que esa significación social -que constituye el valor objetivo-, se refleja en la conciencia individual o colectiva. En dependencia de

\footnotetext{
70. Véase Francisco Javier Díaz-Revorio, supra, nota 25. Pág. 14. 71. Véase José Ramón Fabelo-Corzo, supra, nota 6. Págs. 41, 43, 47 y 48.
} 
los gustos, las aspiraciones, los deseos, las necesidades, los intereses e ideales, cada sujeto social valora la realidad de un modo específico. Como resultado, conforma su propio sistema subjetivo de valores al regular su conducta humana, que pueden poseer mayor o menor grado de correspondencia con el sistema objetivo de valores, en dependencia del nivel de coincidencia de los intereses particulares del sujeto con los de la sociedad.

Según Fabelo-Corzo, ${ }^{72}$ si existiera la posibilidad de que cada sujeto actuase con absoluta libertad en atención a su sistema subjetivo de valores, existiría una sociedad en la que todos halarían para su lado, de acuerdo con la interpretación que cada cual tenga de lo valioso. Por esa razón, la sociedad tiende a organizarse y funcionar en un sistema de valores oficialmente reconocido, el cual puede ser el resultado de la generalización de una de las escalas subjetivas existentes en la sociedad, o de la combinación de varias. Así, suele suceder que los individuos o grupos que ostentan el poder, impongan sus valores al resto y los convierten en oficiales. Cuando el marco de referencia es el de Estado-nación, el sistema institucionalizado de valores se expresa por medio de la ideología oficial, la política, el derecho, la educación y otras vías, de modo que se presenta como universalmente valioso, pero no siempre lo es en realidad, por lo que este sistema oficial puede también tener un mayor o menor grado de correspondencia con el sistema objetivo de valores, en dependencia de qué grupo ostenta el poder y para qué lo utiliza.

El caso concreto de la constitucionalización de los valores en diversos ordenamientos jurídicos constituye uno de los ejemplos de valores instituidos y oficialmente reconocidos que han sido productos de procesos o acontecimientos de la vida social, de necesidades e intereses de la sociedad con significación social, o bien impuestos por quienes detenten el poder, y cómo se caracterizó el proceso constituyente que conllevó al reconocimiento constitucional de esos valores. Se trata de valores que logran expresarse no solo por medio del derecho, sino también por las otras vías explicadas por el citado autor. Si bien es cierto que los valores, al igual que los principios, se han mencionado en normas constitucionales más antiguas en las que aparecen como los ideales de un pueblo recogidos por el constituyente, ${ }^{73}$ es en el constitucionalismo contemporáneo en que comienzan a estudiarse desde

\footnotetext{
72. Id. Págs. 49 y 50.

73. Cf. Marta Silvia Moreno-Luce. La importancia de los valores $y$ principios del derecho en la administración de justicia. Revista Letras Jurídicas 6. Julio-diciembre de 2002. Pág. 4.
}

diferentes ópticas, cambiando incluso el concepto de Constitución por otro más actual. ${ }^{74}$ Por tanto, vale preguntarse: ¿el reconocimiento de los valores por las constituciones es producto del azar histórico? ¿Por qué han adquirido el apelativo de superiores o supremos del ordenamiento jurídico? ¿Los valores constitucionales forman parte del derecho positivo? ¿Basta con el reconocimiento constitucional de los valores para lograr su efectiva consecución? ¿Qué implica el reconocimiento constitucional de los valores en materia de derechos? ¿Realmente deben tener repercusiones en la práctica judicial, la jurídica general, o mejor, en todos los órdenes constituidos o derivados de la Constitución?

\section{LOS VALORES SUPERIORES: UN INTENTO DE REDEFINICIÓN COMO PARTE DE LA IDENTIDAD Y EL PATRIMONIO DE LOS PUEBLOS}

La constitucionalización de los valores como fenómeno extendido en el pasado siglo y en el presente no es un producto del azar histórico. Varios hechos que ensombrecieron la historia del siglo $\mathrm{xx}$ influyeron notablemente en la manera de concebir el derecho y la Constitución:

Las dos grandes guerras, con todos sus horrores y su menosprecio de la condición humana (...) y la globalización, que puso en evidencia tres mundos profundamente desiguales: el de los países industrializados de alta tecnología, el de los países en vías de desarrollo y el de la humanidad sumergida y miserable. ${ }^{75}$

74. "La Constitución, en suma, no es sino la expresión condensada de toda una serie de valores respecto de los que es presumible un elevado consenso, y que habrían de afectar las dinámicas y relaciones públicas y privadas". Véase Antonio Manuel Peña-Freire. LA garantía en el Estado constitucional de derecho. Trotta. (1977). Pág. 79. "Para el neoconstitucionalismo, solamente existe un modelo legítimo de Constitución: aquella que recoge valores políticos y morales determinados en fórmula de derechos humanos o fundamentales". Véase Pedro Salazar-Ugarte. Sobre el concepto de Constitución. Ed. Jorge Luis Fabra Zamora y Álvaro Núñez Vaquero. Enciclopedia de filosofía y Teoría del Derecho. Volumen I. UnAM, Instituto de Investigaciones Jurídicas. (2015). Pág. 1942.

75. Véase Lautaro Ríos-Álvarez. Trascendencia de los Valores en las Constituciones Políticas de Chile y España. Estudios Constitucionales: Revista del Centro de Estudios ConstituCionales 1. Año 1 de 2003. Pág. 762. 
Las guerras mundiales, especialmente la segunda, junto con las guerras y dictaduras suscitadas en diversas regiones del orbe - como el caso de numerosos países de Latinoamérica-, generaron una conciencia colectiva internacional que colocó a los derechos humanos en la mira de su protección y eficacia por los Estados, consolidándose como parte integrante de los ordenamientos constitucionales. Las tendencias cada vez mayores de crear tratados y convenciones internacionales, en los que se salvaguardara integralmente la dignidad del ser humano, así como de configurar jurisdicciones constitucionales en las que los derechos fueran también garantizados, transformaron la visión y estructura del derecho imperante hasta esa época. ${ }^{76}$ Estos factores, unidos a otros tales como las grandes revoluciones y conquistas de la humanidad, generaron que los valores y principios se insertaran en los textos constitucionales o, en su defecto, si ya tenían algún tipo de normativización, fueran susceptibles de ser concretizados como exigencias constitucionales ineludibles, por medio de leyes y demás disposiciones jurídicas, resoluciones judiciales y políticas públicas.

Numerosos sistemas jurídicos se fueron constitucionalizando en un mayor grado y edificaron su actuar y esencia en y hacia la Norma Suprema, no solo en el orden de prelación como Norma Primaria, sino como fuente difuminadora de valores y principios, los cuales encuentran en la Constitución el espacio idóneo para alcanzar su eficacia y plenitud como factores rectores:

Esta visión de supremacía de la Constitución es la que ha permeado en los últimos años, acentuándose durante el siglo $\mathrm{xx}$, donde los derechos humanos fueron exaltados como elementos universales de eficacia y valor pleno en todo sistema jurídico. Hoy más que nunca se concibe a la Constitución como contenedora de valores y principios, es decir, en un aspecto material más que formal. ${ }^{77}$

Este aspecto material es lo que ha conllevado a reformulaciones sobre su concepto y contenido, lo

\footnotetext{
76. Además de estos factores, la doctrina añade otro: la crisis del positivismo jurídico como corriente jurídica predominante. Cf. Manuel Atienza y Juan Ruiz Manero. Dejemos atrás el positivismo jurídico. Isonomía 27. Octubre de 2007. Pág. 7; y cf. Mariano García Canales. Principios generales y principios constitucionales. Revista de Estudios Políticos (Nueva Época) 64. Abril-junio de 1989. Pág. 132

77. Véase Marcos Francisco Del Rosario-Rodríguez. La supremacía constitucional: naturaleza y alcances. DíkAION 20(1). Año 25. Junio de 2011. Pág. 101.
}

cual incide en una de sus más notables características: su supremacía (la que, en definitiva, radica en las dos vertientes). La Constitución es formal, entre otros aspectos, por ser una ley que, a diferencia de otras, fundamenta y ordena la validez de todo un sistema jurídico y establece un procedimiento dificultoso para su reforma, así como los criterios para la creación de otras normas. En otro sentido, es material, ya que en ella se concentran los valores y principios fundamentales que rigen a una organización político-social.

La visión de supremacía de la Constitución como ente material ha permitido la protección progresiva de principios y derechos. Sin embargo, no puede determinarse solo en un sentido formal o material, sino, por el contrario, se explica a partir de los dos. La Constitución es también suprema por los valores y principios que alberga; por esta razón, debe contener una fuerza normativa lo suficientemente eficaz que permita el funcionamiento estructural del sistema jurídico. El constitucionalismo contemporáneo no niega que la Constitución deba poseer una fuerza soberana y constituyente para nacer y subsistir. A estos elementos han de sumárseles los factores de índole axiológico y material contenidos en ella - como consecuencia de un ejercicio soberano legitimador que construyó una estructura normativa superior-, los que, en conjunto, hacen existir y permanecer al orden constitucional como factor supremo. Estos factores axiológicos vienen a constituir en realidad lo verdaderamente supremo, la razón de ser de la Ley Fundamental. La Constitución no será suprema solo por su carácter de norma fundante, sino que lo será en la medida en que aloja elementos axiológicos que incidan en la vigencia y protección de los derechos humanos, armonizados con los criterios internacionales en dicha materia. ${ }^{78}$

Los valores constitucionales fundamentan el reconocimiento, la protección y la efectividad de los derechos humanos. Díaz-Revorio ${ }^{79}$ explica que estos últimos, además de ser derechos subjetivos del individuo, presentan actualmente una dimensión objetiva para varios ordenamientos, desarrollada por la doctrina y la jurisprudencia del Tribunal Constitucional Federal Alemán. Ello conlleva una carga axiológica, al suponer que los derechos constituyen el reflejo y desarrollo del sistema constitucional de valores. Por eso se plantea que "los valores constituyen el fundamento que sostiene el edificio de derechos en el texto

\footnotetext{
78. Id. Págs. 101, 102, 110, 111 y 115.

79. Cf. el Capítulo 5 del libro de Francisco Javier Díaz-Revorio. VALORES SUPERIORES E INTERPRETACIÓN CONSTITUCIONAL. Centro de Estudios Políticos y Constitucionales. Madrid. (1997).
} 
constitucional" ${ }^{80} \mathrm{y}$ cómo el ámbito en el que mayores son las influencias interpretativas de los valores superiores es el de los derechos humanos. ${ }^{81}$ No obstante, los derechos como valores, y la comprensión del sistema de derechos constitucionales en cuanto orden objetivo de valores han recibido críticas, de las cuales la más radical es aquélla que considera que esta comprensión socava los principios del Estado de derecho (desarrollada por Böckenförde), y la expuesta por Habermas, en el sentido en que la comprensión metodológica de los derechos como valores es errada. ${ }^{82}$

Ciertamente, como plantea Lucas Verdú, ${ }^{83}$ desde el punto de vista conceptual los valores constitucionales se diferencian de los derechos - aunque se relacionan con ellos-, en atención a tres razones: 1) porque les sirven de fundamento, 2) porque inspiran su perfeccionamiento y 3) porque ayudan a su interpretación. El reconocimiento constitucional de valores permite la continua evolución e incorporación de derechos y sus garantías a la Constitución y al ordenamiento derivado. No obstante, la dimensión objetiva y axiológica de los derechos no depende de la constitucionalización de valores superiores, en el sentido en que los propios derechos expresan o reflejan una serie de valores, con independencia del reconocimiento de estos. Por ello, los valores superiores intensifican o maximizan las consecuencias de la regulación de los derechos, e influyen en su interpretación y aplicación.

Vale aclarar que, tal como afirma VillabellaArmengol:

La teoría de los valores en el marco del Derecho Constitucional, constituye un tópico cuya aceptación no ha sido pacífica, y su normativización es una de las más recientes innovaciones de la teoría constitucional; la que ha avanzado a su vez de la idea de postularlos como normas de segundo grado con solo un significado teleológico, a considerarlos como precep-

80. Véase Carlos Villabella-Armengol. La axiología de los derechos humanos en Cuba. Comp. Lissette Pérez-Hernández y Martha Prieto-Valdés. Temas de Derecho Constitucional Cubano. Félix Varela. (2002). Pág. 295.

81. Véase José Juan Anzures-Gurría. La eficacia horizontal de los derechos fundamentales. Cuestiones Constitucionales: Revista mexicana de Derecho Constitucional 22. Enerojunio de 2010. Págs. 13-15.

82. Véase Pablo Marshall-Barberán. Los derechos fundamentales como valores. Revista Telemática de Filosofía del Derecho 10. 2006/2007. Págs. 219-222.

83. Véase Pablo Lucas Verdú. Estimativa y política ConstiTuCionales. UCM. Facultad de Derecho. Sección de Publicaciones. (1984). Págs. 100-118. tos con eficacia directa, que impone a los operadores jurídicos y políticos la obligación de procurarlos y desarrollarlos. $^{84}$

En efecto, aún se encuentran quienes ${ }^{85}$ se oponen diametralmente a que los valores formen parte del derecho positivo. Por ejemplo, Martínez-Roldán ${ }^{86}$ plantea que le llama la atención cómo se ha ido diluyendo el derecho en un mundo de pura ideología, cuando no de pura utopía, llegándose a afirmar que esa ideología o esa utopía son auténticas normas jurídicas, simplemente porque están recogidas en algún texto jurídico positivo. Declara abiertamente no compartir el núcleo fuerte de esta teoría - la positivización de los valores, los valores como normas jurídico-positivas, etc.-, a pesar de que reconoce que en la actualidad la opinión más generalizada sea otra. El autor parece defender una posición al extremo legalista del sistema jurídico. Sin embargo, no tiene en cuenta que la Constitución es una Ley, y todo su contenido es derecho positivo, además de que no se trata de una ley cualquiera, sino la más importante de todas las leyes. En contraposición de una concepción legalista, se encuentra la constitucionalista, a la que los autores de este artículo se adhieren en estas reflexiones.

Ahora bien, en relación con la fuerza vinculante de la Constitución, Guastini ${ }^{87}$ explica que no siempre los principios y las disposiciones programáticas contenidas en ella se consideran como normas jurídicas genuinas, vinculantes para todos sus destinatarios y capaces de producir efectos jurídicos. Para algunos no son capaces de provocar ni la abrogación de leyes incompatibles anteriores a la Constitución, ni la invalidez de leyes incompatibles sucesivas; y según ciertas doctrinas, las constituciones no son más que un "manifiesto" político cuya concretización es tarea exclusiva del legislador, por lo que los tribunales no deben aplicar las normas constitucionales carentes de cualquier efecto inmediato, sino solo las normas

84. Véase Carlos Villabella-Armengol, supra, nota 83. Págs. 291 y 292.

85. Véase Sergio Estrada-Vélez. La noción de principios y valores en la jurisprudencia de la Corte Constitucional. Revista FACUltad de Derecho y Ciencias Políticas 41(114). Enero-junio de 2011. Pág. 72.

86. Cf. Luis Martínez Roldán. Valores y normas jurídicas. Derechos y Libertades: ReVista de Filosofía DEL DERECHO Y Derechos humanos 19. Época II. Junio de 2008. Págs. 101, 111, $114,115,121$ y 122 .

87. Riccardo Guastini. La constitucionalización del ordenamiento jurídico: el caso italiano. Estudios DE TEORÍA CONSTITUCIONAL. UNAM, Instituto de Investigaciones Jurídicas. (2001). Págs. 157 y 158. 
que se recogen por las leyes. Según Guastini, "uno de los elementos esenciales del proceso de constitucionalización es precisamente la difusión, en el seno de la cultura jurídica, de la idea opuesta, es decir, de la idea de que toda norma constitucional -independientemente de su estructura o de su contenido normativo- es una norma jurídica genuina, vinculante y susceptible de producir efectos jurídicos" ${ }^{88}$

Por su parte, Alexy ${ }^{89}$ sostiene que el ejemplo más importante de una posición constitucionalista lo ofrece la axiología del Tribunal Constitucional Federal Alemán. De acuerdo con su concepción, la Ley Fundamental de Bonn contiene, en su capítulo sobre derechos fundamentales, un orden objetivo de valores que, en cuanto decisión iusconstitucional fundamental, vale para todos los ámbitos del derecho:

La suposición de que, además de las normas de tipo tradicional, al sistema jurídico pertenecen también valores que, en tanto valores de rango constitucional, ejercen un «efecto de irradiación» en todo el derecho ordinario, tiene amplias consecuencias. La Constitución no es ya sólo base de autorización y marco del derecho ordinario. Con conceptos tales como los de dignidad, libertad e igualdad y de Estado de derecho, democracia y Estado social, la Constitución proporciona un contenido substancial al sistema jurídico. En la aplicación del derecho, esto se muestra en la omnipresencia de la máxima de proporcionalidad, y su tendencia ínsita a reemplazar la subsunción clásica bajo reglas jurídicas, por una ponderación según valores y principios constitucionales..$^{90}$

Ríos-Álvarez afirma que "los valores son el imán que orienta la finalidad de las normas. Sin embargo, cuando están positivados - como en España y en Chile - ingresan al campo de las normas, con el rango y la fuerza vinculante de éstas" ${ }^{91}$ De acuerdo

\footnotetext{
88. Id. Pág. 158.

89. Este autor -al considerar a la República Federal de Alemania- explica que pueden distinguirse dos concepciones básicas del sistema jurídico: la del constitucionalismo y la del legalismo como crítica en contra de la concepción constitucionalista del sistema jurídico. Explica que la posición legalista puede resumirse en cuatro breves fórmulas: 1 . Norma en vez de valor; 2 . Subsunción en vez de ponderación; 3. Independencia del derecho ordinario en vez de la omnipresencia de la Constitución; y 4. Autonomía del legislador democrático dentro del marco de la Constitución, en lugar de la omnipotencia judicial apoyada en la Constitución, sobre todo del Tribunal Constitucional Federal. Véase Robert Alexy. EL CONCEPTO y la validez del Derecho. $2^{\text {a }}$ ed. Gedisa S. A. (2004). Págs. 159-161.

90. Id. Pág. 159.

91. Véase Lautaro Ríos-Álvarez, supra, nota 78. Pág. 761.
}

con Díaz-Revorio, aunque el significado de los valores no tenga la precisión y concreción de otros conceptos jurídicos, tampoco es tan absolutamente ambiguo que puedan convertirse en conceptos vacíos. Al contrario, existen ciertos elementos (entre los que puede destacarse el propio contexto constitucional de los valores, así como la concepción que tiene la sociedad sobre ellos en un momento dado), que permiten precisar de manera aceptable su significado, y determinar así cuáles son las opciones axiológicas fundamentales de la Constitución, las cuales suponen mandatos a todos los poderes públicos. Culmina al afirmar que, "en realidad, la propia positivación de los valores los convierte en elementos jurídicos". ${ }^{92}$

Por su parte, el propio Peces-Barba ${ }^{93}$ se pregunta: ¿qué relevancia tiene esa integración normativa de los valores? ¿Qué pasa en el funcionamiento del derecho, especialmente en el proceso de creación, interpretación y aplicación? A lo que responde que esta inclusión de los valores superiores en una norma jurídica supone la positivación de los fundamentos de justicia de un sistema político mediante su ordenamiento jurídico, por lo que no deben ser entendidos de forma abstracta, sino concretados en la historia de la comunidad. Al estar positivizados, se configuran como una auténtica norma jurídica con un contenido objetivo y material, hasta el extremo de erigirse como norma jurídica básica de la que dependen todas las demás normas del sistema. Así, se desarrollan por las demás normas del ordenamiento y la jurisprudencia que las aplica con el fin de ampliar y profundizar su sentido. La función de los destinatarios (que son todos los operadores jurídicos, todas las instituciones, autoridades y funcionarios), será la de aplicar e interpretar ese artículo que reconoce los valores superiores, al crear o aplicar el derecho. Por tanto, defiende que se trata de una norma del tipo de las definitorias o determinativas, las cuales definen o determinan los contenidos del derecho, por lo que todas las normas inferiores a la Constitución que no estén en conformidad o sean opuestas a los valores superiores, suponen normas inválidas o nulas.

Puede concluirse entonces que el carácter normativo de los valores constitucionales ha sido reconocido por la doctrina mayoritaria: "Los valores constitucionales son normas prescriptivas y vinculantes, orientadas a la producción de normas. Difieren, no obstante los autores, en la eficacia jurídica que la

\footnotetext{
92. Véase Francisco Javier Díaz-Revorio, supra, nota 25. Págs. 46 y 49 .

93. Véase Gregorio Peces-Barba Martínez, supra, nota 71. Pág. 374,379 y 380 .
} 
proclamación constitucional entraña". ${ }^{94}$ En este sentido, la mayoría les reconoce una eficacia meramente limitada al ámbito interpretativo. Sin embargo, como acertadamente advierte Parejo-Alfonso, reducirlos a esto supone "negar la normatividad de los valores o al menos limitarla muy seriamente". ${ }^{95} \mathrm{Si}$ bien es cierto que los valores constitucionales tienen un contenido moral, aparte del jurídico, en su análisis como normas jurídicas adquiere principal importancia su condición de prescripciones jurídicas. Desde este punto de vista, están plenamente situados en el ámbito del derecho, no son meras normas programáticas y su cumplimiento puede exigirse judicialmente. Ciertamente, la mayor o menor densidad prescriptiva de los valores, facilitará o dificultará su aplicación en casos concretos, pero no son categorías jurídicas diferentes, y no puede atribuírseles distinta eficacia jurídica. ${ }^{96}$

La vinculación inmediata de la jurisdicción al orden normativo constitucional y, por tanto, también a sus valores y principios, está en la base de lo que se ha denominado el paso del Estado legislativo al Estado constitucional. Una vez superada la concepción clásica de la ley, no parece posible negar eficacia jurídica dinámica a los valores que fundamentan los distintos textos positivos, con el fin de adecuar estos a la sociedad. $^{97}$

Hasta la fecha, la doctrina ${ }^{98}$ ha realizado investigaciones dirigidas a examinar el proceso de inclusión o reconocimiento de los valores en las constituciones, así como a lograr su definición. Por ejemplo, para Peces-Barba, las constituciones modernas contienen en sus ordenamientos la expresión de los valores que un país aspira a realizar y, en este contexto, se

94. Véase Petra María Thomás-Puig. Valores y Principios Constitucionales. Anuario Parlamento y Constitución 5. 2001. Pág. 139. Son varios los autores que favorecen la positivación constitucional de los valores. Cf. Teresa Freixes-Sanjuán y Jose Carlos Remotti-Carbonell. Los valores y principios en la interpretación constitucional. Revista Española de Derecho Constitucional 35. Año 12. Mayo-agosto de 1992. Pág. 98; Antonio Ruggeri Balances entre valores constitucionales y teorías de las fuentes. Teoría y Realidad Constitucional 12-13. 2004. Pág. 157; Manuel Aragón. Constitución, Democracia y Control. UnAm, Instituto de Investigaciones Jurídicas. (2002). Pág. 52.

95. Véase Luciano Parejo-Alfonso, supra, nota 17. Pág. 124.

96. Véase Luis Prieto-Sanchís. SOBRE PRINCIPIOS y NORMAS Centro de Estudios Constitucionales. (1992). Pág. 141.

97. Véase Petra María Thomás-Puig, supra, nota 97. Pág. 130.

98. Véase Luciano Parejo-Alfonso, supra, nota 17. Este autor desarrolló un abarcador estudio sobre los debates en torno a la formulación del artículo 1.1, y otros de la actual Constitución Española de 1978, en los que se recogen los valores superiores del ordenamiento jurídico español. denominan "valores superiores", en el sentido en que "supone un concepto del derecho como fenómeno cultural, como obra de los hombres en la historia. Los valores superiores son los objetivos máximos"; 99 así como "representan los ideales que una comunidad decide erigir como sus máximos objetivos a desarrollar por el ordenamiento jurídico". 100 Son el fundamento y la meta, el fin del derecho, que el legislador constituyente, expresión de la soberanía, se propone. ${ }^{101}$

Parejo-Alfonso sostiene que representan "una opción consciente por un orden constitucional, y desde él un orden total jurídico, que superando cualquier formalismo descansa y se nutre de aspiraciones y metas ideales, contenidos espirituales sociales, estimados comunes sobre la base del consenso alcanzado en el momento constituyente". ${ }^{102}$ En la misma línea de pensamiento, del Rosario plantea que los valores constitucionales, "dan sustento y razón de ser al sistema constitucional, pues expresan no solo los anhelos sociales más arraigados o trascendentales para una comunidad política determinada, sino también aquellos que son universales e inherentes a la persona". ${ }^{103}$ Para Ríos-Álvarez, "los valores inspiran y exaltan los momentos más nobles y decisivos en la historia de una nación". ${ }^{104}$

Por su parte, un colectivo de autores cubanos ${ }^{105}$ argumenta que los valores superiores son aquellos que

99. Véase Gregorio Peces-Barba Martínez. InTroducción A LA Filosofía del Derecho. Editorial Debate. (1990). Pág. 56.

100. Id. Pág. 42.

101. Este autor, en otros de sus escritos, explica los valores de Europa, y cuáles factores han incidido en su desarrollo, fundamentalmente como un sistema de valores comunes que luego se ha transmitido a otra serie de regiones del universo con una pretensión de universalidad. Véase Gregorio Peces-Barba Martínez. Los valores de Europa. AnUario Residencia de Estudiantes “Fernando de Los Ríos” de 1995-1996. Págs. 173-187.

102. Véase Luciano Parejo-Alfonso, supra, nota 17. Pág. 45.

103. Véase Marcos Francisco Del Rosario-Rodríguez, supra, nota 80. Pág. 100.

104. "Presiden en España la instauración del Estado Social y democrático de Derecho. Iluminan la Declaración de la Independencia (1776) y luego el Preámbulo de la Constitución de los EE. uU. de 1787; se graban a sangre y fuego en el lema de la Revolución francesa (1789); subyacen en el Bill of Rights (1689) y en la legendaria Carta Magna Británica (1215)". Véase Lautaro Ríos-Álvarez, supra, nota 78. Pág. 761.

105. Véase Ángel Mariño-Castellanos, Josefina Méndez-López y Danelia Cutié-Mustelier. Los valores superiores del ordenamiento jurídico, pilar básico del texto constitucional. REvista BARCO DE Papel. Memorias de la iv Conferencia Científica sobre Derecho. Facultad de Derecho de la Universidad De Oriente-Facultad de Derecho Eugenio María de Hostos. Mayagüez de Puerto Rico. 6 -8 De octubre De 1997. Págs. 149 y 150 . 
sirven de sustento jurídico e ideológico a un derecho concreto, y rigen su existencia y realización; en esto reflejan el pensamiento iusfilosófico que promueve la Norma Suprema, al ser un conjunto de postulados producto de una concepción determinada, y que se manifiestan al establecerse la regulación en que ha de desenvolverse la relación entre el ciudadano, el Estado y la sociedad en general. Por tanto, dichos valores son el soporte y fin mismo del ordenamiento, de modo que constituyen un mandato al Estado para que realice su efectiva conquista y consolidación.

¿Por qué se denominan a estos valores con el apelativo de "superiores" o "supremos" del ordenamiento jurídico? Hay quienes opinan ${ }^{106}$ que se debe al hecho de encontrarse recogidos en la Ley Suprema, y que es con la consolidación del constitucionalismo contemporáneo cuando refuerzan su relación con el concepto de supremacía constitucional. Otros ${ }^{107}$ consideran que al denominar a estos valores como "superiores", se indica que existen implícitamente en el texto constitucional otros valores que no llevan este apelativo, como, por ejemplo, los que están reconocidos en un precepto constitucional determinado, por lo que en consecuencia deben reconducirse a los positivados como los de mayor jerarquía. En tanto, otra opinión ${ }^{108}$ se encamina a considerar que los valores en el texto constitucional que no lleven este apelativo son igualmente valores constitucionales que tendrán en el sistema de fuentes la superioridad jerárquica de la Constitución. También se encuentran autores ${ }^{109}$ que explican cómo el término implica un lugar jerárquico con respecto a otros valores también denominados "superiores", los cuales, a diferencia de los constitucionales, subyacen en la sociedad y se enriquecen en la cultura y en la historia por el esfuerzo y la reflexión de los seres humanos, y pretenden convertirse en valores legalizados. No faltan quienes sostienen ${ }^{110}$ que el patronímico se debe a la formulación del Artículo 1.1 de la Constitución española, considerándola como sin precedentes en el derecho comparado, al servir de inspiración para el uso de dicho apelativo por otras constituciones posteriores del orbe, como es el caso

106. Véase Marcos Francisco Del Rosario-Rodríguez, supra, nota 80. Pág. 111.

107. Véase Teresa Freixes-Sanjuán y Jose Carlos RemottiCarbonell, supra, nota 97. Pág. 100.

108. Véase Petra María Thomás-Puig, supra, nota 97. Pág.143.

109. Véase Gregorio Peces-Barba Martínez, supra, nota 71. Pág. 380.

110. "El panorama del Derecho histórico español y del Derecho comparado pone de relieve la inexistencia absoluta de precedentes del artículo 1-1. Es una aportación original del constitucionalismo español a la cultura jurídica y política contemporáneas". Id. p. 374. de las latinoamericanas. Por último, se ha manejado el criterio ${ }^{111}$ según el cual el apelativo indica que se trata de valores que se deben considerar superiores y anteriores a la propia Constitución misma.

Ciertamente, los valores reconocidos constitucionalmente responden a condicionantes históricas, políticas, económicas y socio-culturales concretas en una determinada sociedad. Las definiciones doctrinales expuestas sobre los valores superiores contienen denominadores comunes, en el sentido en que dichos valores expresan ideologías, representan ideales, contenidos espirituales sociales, aspiraciones, metas y anhelos sociales más arraigados o trascendentales de una comunidad, pueblo o nación, así como resultados de la obra de los seres humanos en su historia e inspiradores de momentos históricos insignes y decisivos, reflejos de pensamientos sociales, políticos e iusfilosóficos productos de una concepción determinada, expresión del poder constituyente, estimados comunes sobre la base del consenso, objetivos máximos, mandatos, fundamentos, fines, sustento ideológico, de validez y razón de ser del Estado, el derecho y de todos los órdenes derivados de la Constitución para su efectiva conquista, realización y consolidación. ${ }^{12}$

Por tanto, una vez dichos valores se instituyen y oficialmente se reconocen en la Constitución, deben gozar de la superioridad jerárquica característica de esta, incluso si se trata de los valores recogidos en el Preámbulo. ${ }^{113}$ Por eso, son "valores superiores o

111. Véase Pablo Lucas Verdú. Estudio sobre los valores superiores del ordenamiento constitucional español. Artículo 1.1. ANALES DE LA Real Academia de Ciencias Morales y Políticas 86. Año lXi. 2009. Pág. 78.

112. En Colombia, explica Fayad-Sandoval, la positivización constitucional de un catálogo de principios y valores como reconocimiento de la dignidad humana, "generó nuevas realidades tanto para la sociedad como para el operador judicial, quien, a la hora realizar su trabajo, se aparta de la concepción tradicional del derecho, dejando de percibirlo como ese ideal deontológico dado de buena fe por el legislador, para regular de manera general y abstracta, por medio de imperativos categóricos, relaciones sociales desde la perspectiva del interés general como medio para garantizar condiciones de equidad y justicia entre los seres humanos". Freddy Fernando Fayad-Sandoval. Hermenéutica: el aporte alemán a la interpretación de la ley. Dixi 15(18). Julio-diciembre de 2013. Pág. 134.

113. Por ejemplo, en Colombia, Cabrera sostiene que, "en la Carta Magna de 1991, a partir del preámbulo, cuya fuerza vinculante ha sido reconocido explícitamente por la Corte Constitucional, ha quedado claro que la base misma del sistema jurídico tiene por propósito asegurar los valores de la vida, la convivencia, el trabajo, la justicia, la igualdad, el conocimiento, la libertad y la paz, y que ello se hace en desarrollo de unos principios fundamentales y dentro del esquema de un orden político, económico y social justo". Lizandro Cabrera. El control de convencionalidad y la protección de los derechos humanos en Colombia. Dixi 16(19). Enero-junio de 2014. Pág. 66. 
supremos del ordenamiento jurídico". Sin embargo, no todas las formulaciones constitucionales de reconocimiento de valores han empleado el apelativo "superiores", como en efecto sí lo hizo por primera vez la Constitución Española de 1978, pues las hay que ni siquiera emplean el término, pero se establece por la doctrina y la jurisprudencia que son esos los superiores del ordenamiento, a lo que se suma que ciertamente pueden encontrarse constituciones con reconocimiento de valores en varias partes de su texto. Debido a estas situaciones es que debe considerarse que todos los valores reconocidos - bien sea con o sin el patronímico de superiores, o bien aquellos implícitos en una Constitución-, son valores constitucionales y, por tanto, tienen la supremacía jerárquica de la fuente de donde provienen. Estos valores constitucionales son a la vez los valores superiores o supremos de todo el ordenamiento jurídico, político, económico, social y cultural de un país determinado, por el tipo de ley en el que se recogen. En el caso de aquellas constituciones que reputan como superiores unos valores y contienen a la vez otros implícitos en su texto, al ser ambos casos valores constitucionales, en supuestos de conflictos entre ellos en la decisión de un caso concreto, deben armonizarse y aplicar aquel o aquellos que se consideren más adecuados y beneficiosos para su solución, con la imprescindible motivación y argumentación de la decisión. ${ }^{114}$

114. La vigente Constitución de Venezuela es una de las que especifica, en el Artículo 2, cuáles son sus valores superiores del ordenamiento jurídico. Sin embargo, se trata de un texto plagado por el reconocimiento de otros valores implícitos que no están enunciados dentro del mencionado Precepto 2, y, sin embargo, la jurisprudencia de la Sala Constitucional del Tribunal Supremo los ha empleado con primacía en la solución de determinados casos judiciales concretos, con la debida argumentación y armonización con aquellos reputados como superiores. Tal es el caso de determinados valores del Preámbulo tales como la paz, el bien común y la convivencia. Por ejemplo, la Sentencia 85 de 2002 expresa: "El Preámbulo de la Constitución, como tal es parte de ella, y según él, la Constitución es la base para refundar la República de acuerdo a los valores expresados en el mismo Preámbulo. Consecuencia de ello, es que la conceptualización de lo que es Estado Social de Derecho y de Justicia tiene que adaptarse a los valores finalistas del Preámbulo (...) del Preámbulo se colige que el Estado Social está destinado a fomentar la consolidación de (...) la paz, el bien común, la convivencia (...) Luego, la Constitución antepone el bien común (el interés general) al particular, y reconoce que ese bien común se logra manteniendo la solidaridad social, la paz y la convivencia. En consecuencia, las leyes deben tener por norte esos valores, y las que no lo tengan, asi como las conductas que fundadas en alguna norma, atenten contra esos fines, se convierten en inconstitucionales". Véase Tribunal Supremo de Justicia [Sala Constitucional]. Sentencia 85. (Enero 24 del 2002). Disponible en http://vlex.com.ve/tags/valores-supremo-estado-venezolano-3720215/page/2?_ga=1.64528431.1403699 435.1476383772
Son a la vez valores que forman parte de la identidad y el patrimonio ${ }^{115}$ de los pueblos. Si la Constitución es la norma suprema y su peculiaridad reside, entre otras cuestiones, en ser portadora de los valores que son expresión de las aspiraciones, cultura e identidad de una nación - sobre todo si son productos de un proceso constituyente democrático-, entonces dichos valores deben ser considerados como parte del patrimonio de esta. El concepto de patrimonio ha ido evolucionando a lo largo del tiempo e indiscutiblemente tiene que ver con la herencia, y concierne a la personas en razón de su patria, padre o antepasados. La definición de patrimonio como herencia se encuentra dominada por los aspectos sociales y culturales de cada sociedad, como lo son las concepciones del tiempo, del espacio, sus formas de transmisión cultural y los valores. Por eso, el vocablo "patrimonio" es polisémico, según el contexto en el que se expresa, por lo que existen diferentes tipos de patrimonio: patrimonio cultural, patrimonio histórico, patrimonio artístico, patrimonio arquitectónico, etc. Si se tiene en cuenta el concepto de patrimonio en general, el cual comprende bienes tangibles e intangibles heredados, el ambiente donde se vive, los campos, ciudades y pueblos, las tradiciones y creencias que se comparten, los valores, la forma de ver el mundo y adaptarse a él, se trata de bienes que son marcadores de una identidad enraizada en el pasado, actualizada en el presente y reinterpretada por las sucesivas generaciones. ${ }^{116}$

"La Constitución es la expresión de un determinado nivel de desarrollo cultural y de la auto-representación cultural de un pueblo, espejo de su patrimonio y fundamento de sus esperanzas". ${ }^{117} \mathrm{De}$ ahí que se proponga una visión de los valores constitucionales como dimensión intangible del patrimonio de los pueblos, precisamente por ser productos de una cultura, identidad, ideología, de condicionantes históricas, políticas, sociales y económicas concretas. Como patrimonio al fin, la voluntad pública debe encaminarse hacia la eficaz realización de esos valores. ¿Cómo lograr esa pretendida consecución? ¿Acaso basta con el reconocimiento constitucional de los valores?

115. Un autor que emplea el término patrimonio al referirse a los valores es Antonio Ruggeri, supra, nota 97. Pág. 162.

116. Véase Verónica B. Gauchi. Tutela jurídica del PatriMONIO DOCUMENTAL EN LA LEGISLACIÓN SUDAMERICANA. Tesis de la I Maestría en Gestión Documental y Administración de Archivos. Universidad Internacional de Andalucía. (2010). Pág. 7. Disponible en http://dialnet.unirioja.es/servlet/tesis?codigo $=20842$ \&orden $=260903$ \&info $=$ link

117. Id. 33 . 
No basta con el reconocimiento constitucional de los valores para alcanzar su desarrollo efectivo. $\mathrm{Su}$ realización objetiva requiere: que sean tenidos en cuenta en los actos del gobierno, en las funciones legislativas, ejecutivas y judiciales de los órganos del Estado, con el condicionamiento material y sociopolítico para su alcance como vías para satisfacer las aspiraciones sociales; constituyan la base axiológica de los derechos previstos en la Constitución y las demás leyes, sirviéndoles de fundamento y contribuyendo a su interpretación, aplicación, evolución e inclusión de otros derechos inherentes al ser humano reconocidos por los instrumentos internacionales; que fundamenten la necesitad de la creación de garantías para dichos derechos, o el perfeccionamiento de las existentes; sirvan de fuente de inspiración para diseños legislativos que sean fieles reflejos de los fines y mandatos de la Ley Fundamental, y acerquen las normas ordinarias a las constitucionales, y la directa aplicabilidad de estas en todos los órdenes y procesos derivados de la Constitución, como, por ejemplo, en los procesos judiciales, lo que permitirá una mejor consecución del valor "justicia"118 en los juzgamientos. A lo que se suma la posibilidad de que quienes están llamados a interpretar y aplicar las leyes y demás disposiciones jurídicas, puedan recurrir a los valores y principios constitucionales para resolver casos concretos, preconizándolos sobre cualquier norma o disposición lesiva a la Constitución y los derechos humanos, de manera que esto sirva de sustento para la argumentación adecuada de sus decisiones. Como lo plantea Carmona-Tinoco, citando una sentencia:

El exacto cumplimiento de la Constitución sólo puede lograrse si su intérprete, liberándose de las ataduras de quienes se encargan simplemente de aplicar los textos legales (expresión positivizada del derecho), entiende que su función no se agota en la mera subsunción automática del supuesto del hecho al texto normativo, ni tampoco queda encerrada en un positivismo formalizado superado muchas décadas atrás, sino que comprende básicamente una labor de creación del derecho en la búsqueda de la efectiva realización de los valores supremos de la justicia (...)
Así, el intérprete de la Constitución en el trance de aplicarla tiene por misión esencial magnificar los valores y principios inmanentes en la naturaleza de las instituciones, convirtiendo la norma escrita en una expresión del derecho vivo. ${ }^{119}$

\section{Conclusiones}

La relación de los valores con el derecho, la Constitución y el ordenamiento jurídico devienen de una prolongada evolución del pensamiento iusfilosófico mundial, cuyas concepciones están matizadas por contextos históricos e intereses socio-clasistas que ayudan a entender el significado de los valores constitucionales, y sirven de base para su fundamentación y sentido por quienes están llamados a desarrollarlos, interpretarlos y aplicarlos.

La constitucionalización de los valores como tendencia en las últimas décadas no es un producto del azar histórico. Aquellos reconocidos como superiores o los implícitos en una Constitución son valores constitucionales, con la supremacía jerárquica de la fuente de donde provienen, de manera que forman parte del derecho positivo y son directamente invocables, interpretables y aplicables por todos los operadores jurídicos.

Los valores constitucionales fundamentan el reconocimiento, la protección y la efectividad de los derechos, los que presentan una dimensión objetiva en varios ordenamientos, aunque los valores se diferencian de ellos; si bien dichos derechos constituyen a la vez desarrollos, reflejos y realizaciones de los valores.

Los valores reconocidos en las constituciones expresan ideologías, ideales y aspiraciones; son reflejo de pensamientos sociales, políticos e iusfilosóficos y constituyen mandatos al Estado, al derecho, y a todos los órdenes derivados de la Constitución para su efectiva conquista, realización y consolidación, al ser parte de la identidad y del patrimonio intangible de los pueblos.

118. "La virtud de la justicia siempre está ligada al uso que de ella se dé. La justicia, en tanto se considera virtud, sólo lo es de acuerdo con el ejercicio que se haga en su administración y la aceptación social que conlleve. Esto es, requiere de una administración capaz de ordenar de manera tal que la sociedad cree en sus relaciones un sentido material de respeto y obediencia sobre lo decidido". Jesús David Vega-Millán. El bloque de constitucionalidad, la justicia y la seguridad jurídica implícitos en la configuración del funcionario de hecho. Dixi 17(21). Enero-junio de 2015. Pág. 96.

119. Véase aA. vv. V Congreso Iberoamericano de Derecho Constitucional. $1^{\text {a }}$ ed. UnAM, Instituto Iberoamericano de Derecho Constitucional. (1998). Pág. 168. 


\section{REFERENCIAS}

Aa. vv. v Congreso Iberoamericano de Derecho ConsTITUCIONAL. $1^{\text {a }}$ ed. UNAM, Instituto Iberoamericano de Derecho Constitucional. (1998).

Abelardo Torré. Introducción Al Derecho. 14ª ed. Abeledo-Perrot. (2003).

Alfredo Stern. La Filosofía de los valores. Trad. Humberto Piñera-Llera. Minerva. (1944).

Alicia Rendón López. El otro triángulo de las Bermudas: el amor, la felicidad y la justicia social. Revista Amicus Curiae 1. Segunda época 2. 2013.

Andrzej Grabowski. Clasificar valores en el derecho. Sobre la concepción de Manuel Atienza y Juan Ruiz Manero. Doxa 20. 1997. Págs. 443-456.

Ángel Mariño-Castellanos, Josefina Méndez-López y Danelia Cutié-Mustelier. Los valores superiores del ordenamiento jurídico, pilar básico del texto constitucional. Revista Barco de Papel. Memorias de la iv Conferencia Científica sobre Derecho. Facultad de Derecho de la Universidad de Oriente-Facultad de Derecho Eugenio María de Hostos. Mayagüez De Puerto Rico. 6-8 De octubre De 1998. Págs. 149-150.

Antonio Manuel Peña-Freire. LA Garantía en EL Estado CONSTITUCIONAL DE DERECHO. Trotta. (1977).

Antonio Ruggeri. Balances entre valores constitucionales y teorías de las fuentes. Teoría y Realidad ConstituCIONAL 12-13. 2003, segundo semestre. Págs. 155-180.

Aristóteles. Ética A Nicómaco. Edición del Centro de Estudios Constitucionales. (1985).

Bartolo Pablo Rodríguez-Cepeda. Metodología JURídiCA. $7^{\text {a }}$ reimpresión. Oxford University Press. (2006).

Bertrand Russell. Religión y Ciencia. Fondo de Cultura Económica. (1956).

Carlos Cossío. Los valores jurídicos. AnUARIo de Filosofía Del Derecho 4. 1956. Págs. 27-92.

Carlos de la Torre-Martínez. LA RECEPción DE LA FILOSOFÍA DE LOS VALORES EN LA FILOSOFÍA DEL DERECHO UNAM, Instituto de Investigaciones Jurídicas. (2005).

Carlos Santiago Nino. Justicia. Doxa 14. 1993. Págs. 61-74.

Carlos Villabella-Armengol. La axiología de los derechos humanos en Cuba. Comp. Lissette Pérez-Hernández y Martha Prieto-Valdés. Temas de Derecho Constitucional Cubano. Félix Varela. (2002).

Chaim Perelman. De la Justicia. Trad. Ricardo Guerra. Centro de Estudios Filosóficos. UnAM, Dirección General de Publicaciones. (1964).
Constitución Española de 1978 [Const]. (España). Disponible en http://www.boe.es/buscar/pdf/1978/BOE-A1978-31229-consolidado.pdf

Constitución del Salvador de 1983. [Const]. (El Salvador) Disponible en http://pdba.georgetown.edu/Constitutions/ElSal/constitucion.pdf

Constitución Política de Colombia de 1991. [Const]. Julio 7 de 1991. (Colombia). Disponible en http://pdba.georgetown.edu/Constitutions/Colombia/vigente.html

Constitución de la Nación Argentina de 1994. [Const]. (Argentina). Disponible en http://pdba.georgetown.edu/ Constitutions/Argentina/argen94.html

Constitución de la República Bolivariana de Venezuela de 1999. [Const]. (Venezuela). Disponible en http://www. mp.gob.ve/LEYES/constitucion/constitucion1.html

Constitución Política del Estado de Bolivia de 2009. [Const]. (Bolivia). Disponible en http://pdba.georgetown.edu/ Constitutions/Bolivia/bolivia09.html

Constitución de la República Dominicana de 2010. [Const]. (República Dominicana). Disponible en http://pdba. georgetown.edu/Constitutions/DomRep/vigente.html

Corte Constitucional de Colombia. Sentencia 126/98. (MP Alejandro Martínez C.: Abril 1 de 1998). Disponible en http://www.corteconstitucional.gov.co/relatoria/1998/ C-126-98.htm

Corte Constitucional de Colombia. Sentencia 479/13. (MP José G. Hernández y Alejandro Martínez C.: Agosto 13 de 1992). Disponible en http://www.corteconstitucional.gov.co/relatoria/1992/c-479-92.htm

Friedrich August von Hayek. Derecho, LEgISLACIÓN Y LIBERTAD. NORMAS Y ORDEN. VOL. I. Unión Editorial. (1978).

Edmund Husserl. Investigaciones Lógicas. Trad. Manuel García Morente y José Gaos. Alianza. (2001).

Francesco Orestano. Los valores humanos. Trad. Vicente Paúl Quintero. Argos. (1947).

Francisco Javier Díaz-Revorio. VAlORES SUPERIORES E INTERPRETACIÓn CONSTITUCIONAL. Centro de Estudios Políticos y Constitucionales. (1997)

Francisco Javier Díaz-Revorio. Sobre los valores en la Filosofía Jurídica y en el Derecho Constitucional. REvista Brasileira de Direito Constitucional- RbDC 19. Enero/junio de 2012.

Freddy Fernando Fayad-Sandoval. Hermenéutica: el aporte alemán a la interpretación de la ley. Dixi 15(18). Julio-diciembre de 2013. Págs. 133-136.

Gregorio Peces-Barba Martínez. InTroducción A LA FiLOSofía del Derecho. Editorial Debate. (1990). 
Gregorio Peces-Barba Martínez. Los valores de Europa. Anuario Residencia de Estudiantes "Fernando DE LOS Ríos” de 1995-1996. Págs. 173-187.

Gregorio Peces-Barba Martínez. Los valores superiores. Anuario de Filosofía del Derecho 4. 1987. Págs. 373-388.

Gustav Radbruch. El hombre en el Derecho. Depalma. (1980).

Herbert Lionel Adolphus Hart. El Concepto de Derecho. Trad. Genaro R. Carrió. Abeledo-Perrot s. A. (1998).

Herbert Lionel Adolphus Hart. Post ScRíptum al ConCEPTo Del Derecho. Trad. Rolando Tamayo y Salmorán. UNAM, Instituto de Investigaciones Jurídicas. (2000).

Hans Kelsen. Teoría pura del Derecho. Trad. de la $2^{\text {a }}$ ed. en alemán por Roberto J. Vernengo. UNAM, Instituto de Investigaciones Jurídicas. México. (1982).

Hans Kelsen. ¿Qué es la Justicia? Trad. Leonor Calvera. Ediciones elaleph.com. (2000).

Henrich Rickert. Ciencia cultural y Ciencia natural. Espasa-Calpe s. A. (1937).

I. S. Narski. La filosofía de Europa Occidental EN EL SIGLO XVIII. Pueblo y Educación. (1985).

Immanuel Kant. CRÍTICA DE LA RAZÓN PURA. Trad. Manuel G. Morente. Librería General de Victoriano Suárez. (1928). Disponible en http://www.cervantesvirtual. com

Jean Jaques Rousseau. El CONTrato Social. $4^{\mathrm{a}}$ ed. UNAM, Instituto de Investigaciones Jurídicas. (1984).

Julián Marías. Historia DE LA fILOsofía. Alianza Universidad. (1986).

Jesús David Vega-Millán. El bloque de constitucionalidad, la justicia y la seguridad jurídica implícitos en la configuración del funcionario de hecho. Dixi 17(21). Enero-junio de 2015. Págs. 91-104.

John Rawls. Justicia COMO EQUIDAD. MATERIALES PARA UNA TEORÍA DE LA JUSTICIA. Tecnos. (1986)

John Rawls. Teoría de la justicia. Trad. María D. González. Fondo de Cultura Económica. (1979).

John Rawls. LA JUSTICIA COMO EQUIDAD. UNA REFORMULACión. Trad. Andrés de Francisco. Paidós. (2002).

José Juan Anzures-Gurría. La eficacia horizontal de los derechos fundamentales. Cuestiones Constitucionales: Revista mexicana De Derecho Constitucional 22. Enero-junio de 2010.

José Ortega y Gasset. ¿Qué son los valores? Una introducción a la estimativa y España invertebrada. OBRAs COMPLETAs. Revolución de Occidente. (1946-1947).
José Ramón Fabelo-Corzo. Los valores y sus DESAfíos ACTUALES. José Martí. (2003).

Julio Fausto Fernández. Los Valores y el Derecho. Ministerio de Cultura. Departamento Editorial. (1957).

Julio Fernández-Bulté. Filosofía DEL Derecho. Félix Varela. (2005).

Karl Larenz. LA FILOSOFÍA CONTEMPORÁNEA DEL DERECHO y DEL Estado. Trad. Eustaquio Galán-Gutiérrez y Antonio Truyol-Serra. Revista de Derecho Privado de 1942.

Lautaro Ríos-Álvarez. Trascendencia de los valores en las constituciones políticas de Chile y España. Estudios Constitucionales: Revista del Centro de EstuDios Constitucionales 1. Año 1 de 2003. Pág. 757781.

Lizandro Cabrera. El control de convencionalidad y la protección de los derechos humanos en Colombia. DIXI 16(19). Pág. 53-70.

Luciano Parejo-Alfonso. Constitución Y LOS VAlORES DEL ordenamiento. Centro de Estudios Ramón Areces s. A. (1990).

Luis M. Cruz. La Constitución como orden de valores. Reflexiones en torno al neoconstitucionalismo. DíkAION 18. Año 23. Diciembre de 2009. Págs. 11-31.

Luis Martínez-Roldán. Valores y normas jurídicas. DERECHOS y LIBERTADES: REVISTA DE FILOSOFÍA DEL DERECHO Y DERECHOS HUMANOS 19. Época II. Junio de 2008. Págs. 99-122.

Luis Prieto-Sanchís. Sobre PRINCIPIOS Y NORMAS. Centro de Estudios Constitucionales. (1992).

Luis Recasens-Siches. Direcciones ContemporáneAs DEI PENSAMIENTO JURÍDICO. Labor. (1929).

Luis Recaséns-Siches. Tratado general DE Filosofía DEL DERECHO. $15^{\mathrm{a}}$ ed. Porrúa. (2001).

Mariano García-Canales. Principios generales y principios constitucionales. Revista DE Estudios Políticos 64 Nueva época . Abril-junio de 1989.

Manuel Aragón. Constitución, Democracia y Control. UNAM, Instituto de Investigaciones Jurídicas. (2002).

Manuel Atienza y Juan Ruiz Manero. Dejemos atrás el positivismo jurídico. Isonomía 27. Octubre de 2007. Págs. 7-28.

Marcos Francisco del Rosario-Rodríguez. La supremacía constitucional: naturaleza y alcances. DíKAION 20(1). Año 25. Junio de 2011. Págs. 97-117.

María Teresa Vizcaíno-López. InTroducción AL Estudio Del Derecho. Ediciones de la Facultad de Derecho y Ciencias Sociales de la Universidad Michoacana de San Nicolás de Hidalgo. (2009). 
Marta Silvia Moreno-Luce. La importancia de los valores y principios del derecho en la administración de justicia. ReVista Letras Jurídicas 6. Julio-diciembre de 2002.

Max Scheler. Ética. NuEvo ENSAYo DE FUndamentacióN DE Un PERSONALISMO ÉTiCo. Trad. Hilario Rodríguez Sanz. Caparrós. (2001).

Miguel Eduardo Morales-Lizárraga. La controversia Hart-Dworkin en torno a la decisión judicial. Revista Amicus Curiae 2(3). Segunda época. 2013.

Norberto Bobbio. El tiempo De los Derechos. Trad. Rafael de Asís Roig. Editorial Sistema. (1991).

Norberto Bobbio. Igualdad y Libertad. Ediciones Paidós Ibérica S. A., I. C. E./U. A. B. (1993).

Norberto Bobbio. Teoría General del Derecho. Temis (1987).

Pablo Lucas Verdú. Estimativa y Política constitucioNALES. UCM, Facultad de Derecho. (1984).

Pablo Lucas Verdú. Estudio sobre los valores superiores del ordenamiento constitucional español. Artículo 1.1. ANAles de la Real Academia de Ciencias Morales y Políticas 86. Año LXi. 2009.

Pablo Marshall-Barberán. Los derechos fundamentales como valores. Revista Telemática de Filosofía del DeRECHO 10. 2006/2007. Págs. 207-228.

Pedro Salazar-Ugarte. Sobre el concepto de Constitución. Ed. Jorge Luis Fabra-Zamora y Álvaro Núñez-Vaquero. Enciclopedia de filosofía y TeOría del DereCHO. Volumen I. UNAM, Instituto de Investigaciones Jurídicas. (2015).

Petra María Thomás-Puig. Valores y Principios Constitucionales. Anuario Parlamento y Constitución 5. 2001. Págs. 129-143.

Rafael Rojina Villegas. La Justicia, valor supremo del Derecho. Revista de la Escuela Nacional de JURISPRUDENCIA 39 y 40. Tomo x. Julio-diciembre de 1948. Págs. 239-254.

Riccardo Guastini. La constitucionalización del ordenamiento jurídico: el caso italiano. EsTUdIos DE TEORÍA CONSTITUCIONAL. UNAM, Instituto de Investigaciones Jurídicas. (2001)
Risieri Frondizi. Pensamiento axiológico. Antología. Instituto Cubano del Libro-Universidad del Valle. (1993).

Risieri Frondizi.¿QuÉ son LOS VAlOREs? Fondo de Cultura Económica. (1994).

Robert Alexy. El concepto y la VAlidez del Derecho. $2^{a}$ ed. Gedisa s. A. (2004).

Ronald Dworkin. El Imperio de la Justicia. $2^{\text {a }}$ ed. Trad. Claudia Ferrari. Editorial Gedisa s. A. (1992).

Ronald Dworkin. Los Derechos en SERIo. $1^{\mathrm{a}} \mathrm{ed}$. Trad. Marta Guastavino. Ariel s. A. (1984).

Sergio Estrada-Vélez. La noción de principios y valores en la jurisprudencia de la Corte Constitucional. Revista FAcultad de Derecho y Ciencias Políticas 41(114). Enero-junio de 2011.

Teresa Freixes-Sanjuán y Jose Carlos Remotti-Carbonell. Los valores y principios en la interpretación constitucional. Revista Española de Derecho ConstitucioNAL 35. Año 12. Mayo-agosto de 1992.

Urbano Ferrer-Santos. Los valores en el ámbito jurídico. PERSONA Y DERECHO: REVISTA DE FUNDAMENTACIÓN DE LAS Instituciones Jurídicas y DE Derechos HuMANOS 9. 1982. Págs. 93-102.

Valentín F. Asmus. Historia de la filosofía ANTiguA. Pueblo y Educación. (1988)

Verónica B. Gauchi. Tutela JURÍdicA DEL PATRIMONIO DOCUMENTAL EN LA LEGISLACIÓN SUDAMERICANA. Tesis de la I Maestría en Gestión Documental y Administración de Archivos. Universidad Internacional de Andalucía. (2010). Disponible en http://dialnet.unirioja. es $/$ servlet $/$ tesis ? codigo $=20842$ \&orden $=260903 \&$ in fo=link

Tribunal Supremo de Justicia [Sala Constitucional]. SENTENCIA 85. (ENERo 24 del 2002). Disponible en http:// vlex.com.ve/tags/valores-supremo-estado-venezolano-3720215/page/2?_ga=1.64528431.1403699435.14 76383772 